GASKELL

\section{Bereavement Information}

\section{Pack}

\section{For those bereaved through suicide or other sudden death}

\author{
Kate Hill, Keith Hawton, \\ Aslög Malmberg and Sue Simkin
}

It is often difficult for relatives and friends of people who die by suicide or other sudden death to get help. This pack is specifically designed for such people. It highlights the areas of greatest difficulty for the bereaved person and offers advice on how to get support from friends and family and bereavement support and counselling organisations, as well as providing a list of recommended reading. A substantial number of bereaved individuals have already found it helpful. This pack is fully supported by The Samaritans and The Royal College of Psychiatrists.

\section{$£ 5.00 \bullet 1997 \bullet$ ISBN 1901242080}

Gaskell is the imprint of the Royal College of Psychiatrists. Gaskell books are available from good bookshops and from Book Sales, Publications Department, Royal College of Psychiatrists, 17 Belgrave Square, London SWIX $8 P G$ (Tel. $+44(0) 171235$ 2351, extension 146). The latest information on College publications is available on the INTERNET at: www.rcpsych.ac.uk
Epilim Oral Prescribing Information

Presentation Epilim 200 Enteric Coated and Epilim 500 Enteric Coated: Enteric coated tablets containing $200 \mathrm{mg}$, and $500 \mathrm{mg}$ Sodium Valproate Ph.Eur. respectively. Epilim Crushable Tablets containing 100mg Sodium Valproate Ph.Eur. Epilim Syrup and Epilim Liquid (sugar free) both containing $200 \mathrm{mg}$ Sodium Valproate Ph.Eur. per 5ml. Epilim Chrono 200, Epilim Chrono 300, and Epilim Chrono 500: Controlled release tablets containing a mixture of Sodium Valproate Ph.Eur. and Valproic Acid Fr.P. equivalent to $200 \mathrm{mg}, 300 \mathrm{mg}$, and $500 \mathrm{mg}$ Sodium Valproate respectively. Indications Oral formulations of Epilim are indicated for all types of epilepsy. In women of child bearing age Epilim, should be used only in severe cases or in those resistant to other treatment. Dosage and administration Adults; the dose should be titrated at three day intervals until seizure control is achieved. Initially $600 \mathrm{mg}$ a day increasing in steps of $200 \mathrm{mg}$ to a maximum dose of $2500 \mathrm{mg}$ per day. Children over $20 \mathrm{~kg}$; initially $400 \mathrm{mg}$ a day increasing iri steps to a maximum dose of $35 \mathrm{mg} / \mathrm{kg} / \mathrm{day}$. Children under $20 \mathrm{~kg}$; initially $20 \mathrm{mg} / \mathrm{kg} / \mathrm{day}$ - the dose may be increased in severe cases provided that plasma levels are monitored; above $40 \mathrm{mg} / \mathrm{kg} /$ day chemistry and haematology should be monitored. Epilim Chrono may be given once or twice daily. All other formulations should be given twice daily. Combination therapy; levels of Epilim and co-administered anticonvulsants may be affected and optimum dosage is determined by seizure control. Contraindications, Warnings, etc. Contraindications Active liver disease, family history of severe liver disease, porphyria, hypersensitivity to valproate: Side effects Impaired hepatic function, particularly in children, occasionally leading to hepatic failure treatment should be withdrawn in patients who suddenly develop symptoms compatible with hepatic disease such as nausea, anorexia, jaundice or malaise. Hyperammonaemia with or without hepatic dysfunction. Blood dyscrasia - impaired platelet function, thrombocytopenia, occasional leucopenia, pancytopenia and red cell hypoplasia. Occasionally increased appetite, weight gain, transient hair loss, behavioural disturbances, hearing loss, vasculitis, alterations to the menstrual cycle and pancreatitis. Symptoms of intoxication include ataxia, tremor, and stupor. Drug interactions Epilim has significant interactions with phenytoin, lamotrigine and other anticonvulsants. Epilim may potentiate the effects of neuroleptics, MAOls and other antidepressants, anticoagulants and salicylates. Cimetidine and erythromycin may inhibit the metabolism of Epilim. Mefloquine may decrease serum valproate levels. Epilim has no effect on the efficacy of oral contraceptives. Pregnancy An increased incidence of congenital abnormalities has been demonstrated in offspring born to mothers with epilepsy both untreated and treated, including those treated with sodium valproate. Neural tube defects have been reported in about $1-2 \%$ of offspring of women who have received valproate during the first trimester of pregnancy. Pregnancies should be screened for neural tube defects by estimation of alpha-fetoprotein and ultrasound. Folate supplementation has been shown to reduce the incidence of neural tube defects in the offspring of high risk women. Legal category P.O.M. Further information Epilim is hygroscopic - tablets should not be removed from their foil until they are used. Epilim Chrono is recommended in cases where plasma valproate levels are being measured on account of its pharmacokinetics. The effective therapeutic range for valproate is $40-100 \mathrm{mg} /$ (278-694 micromol/l). Product Licence Numbers Epilim 200 Enteric Coated 11723/0018, Epilim 500 Enteric Coated 11723/0020, Epilim 100mg Crushable Tablets 11723/0017, Epilim Syrup 11723/0025, Epilim Liquid 11723/0024, Epilim Chrono 200 11723/0078, Epilim Chrono 300 11723/0021, Epilim Chrono 500 11723/0079. NHS Cost Epilim 200 Enteric Coated 100 tablets 66.42, Epilim 500 Enteric Coated 100 tablets $f_{16.04}$ Epilim $100 \mathrm{mg}$ Crushable Tablets 100 tablets $£^{3.89}$. Epilim Syrup $300 \mathrm{ml} £ 5.89$, Epilim Liquid $300 \mathrm{ml} £^{5.89}$, Epilim Chrono 200100 tablets $£ 7.70$, Epilim Chrono 300100

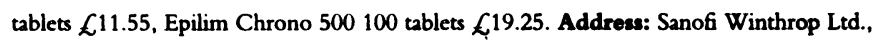
One Onslow Street, Guildford, Surrey GU1 4YS. Telephone: (01483) 505515 Fax: (01483) 35432. Epilim, Epilim Chrono and the Chrono device are registered trade marks. Date of preparation: January 1997.

\section{References:}

1. Chadwick D., J. Neurol. Neurosurg. Psychiatry 1994; 57: 264-277.

2. Gilham R.A., Epilepsy Res., 1990; SANOFI WINTHOP 


\section{Give someone with epilepsy a future to look forward to}

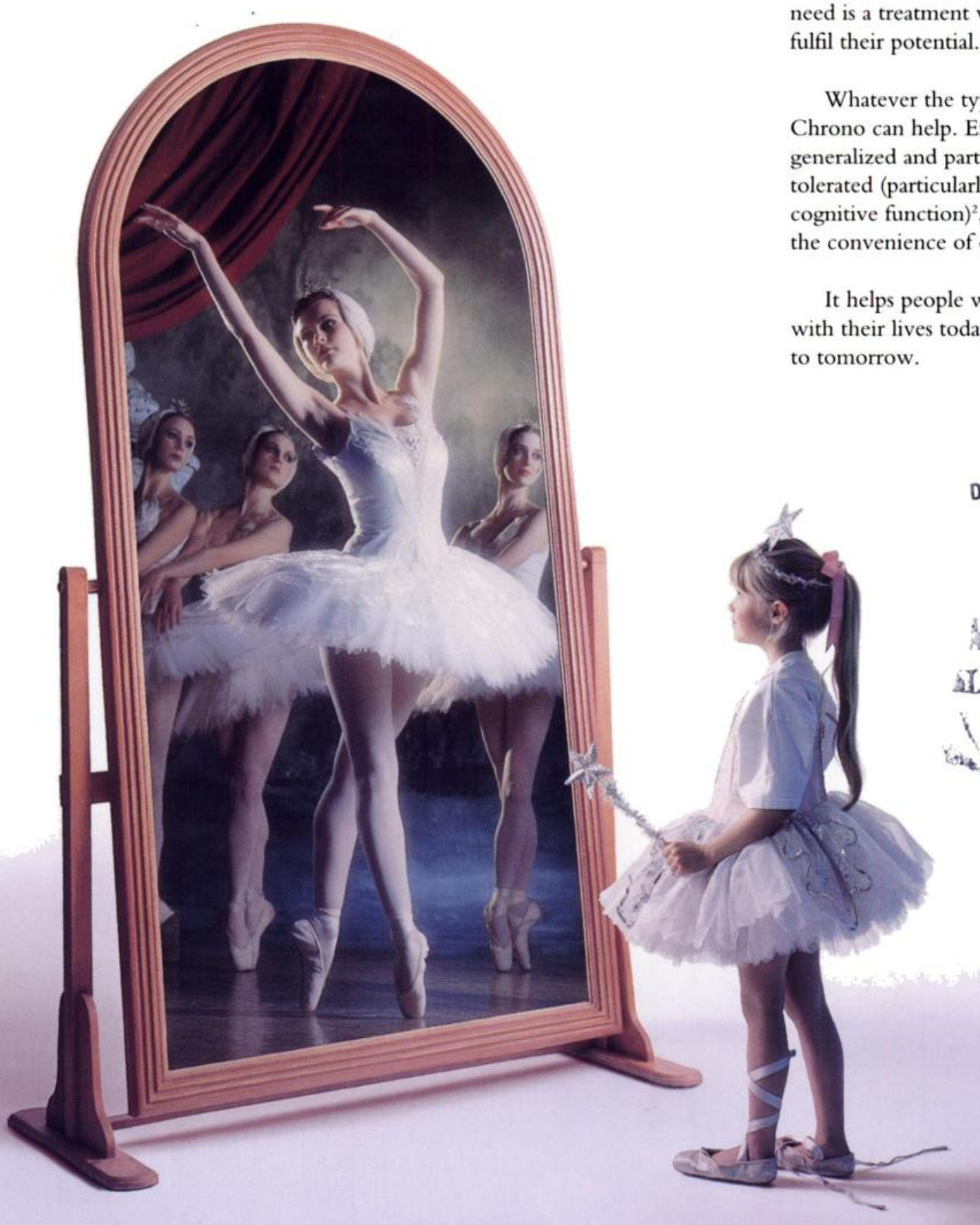

People with epilepsy have the same aspirations as anybody else. What they need is a treatment which allows them to fulfil their potential.

Whatever the type of epilepsy, Epilim Chrono can help. Effective both in generalized and partial seizures, ${ }^{\prime}$ it is well tolerated (particularly with regard to cognitive function $)^{2}$, and offers patients the convenience of once-daily dosing.

It helps people with epilepsy get on with their lives today, and look forward to tomorrow.

DEC 17 is
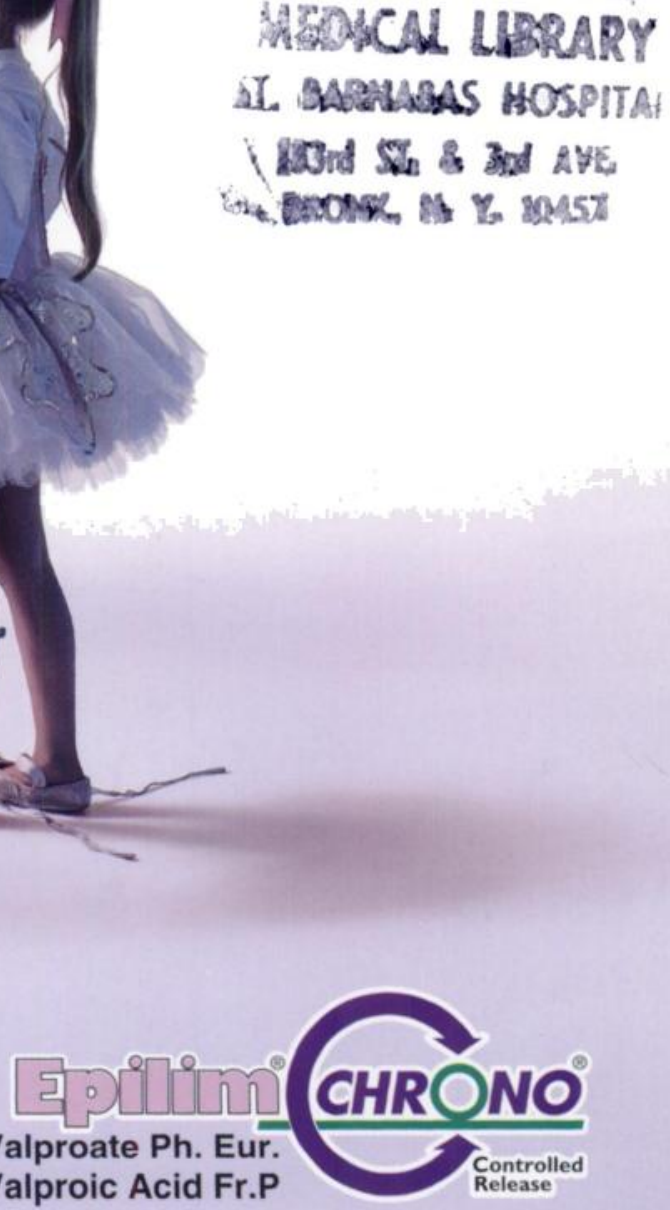

Once-daily management for all forms of epilepsy 


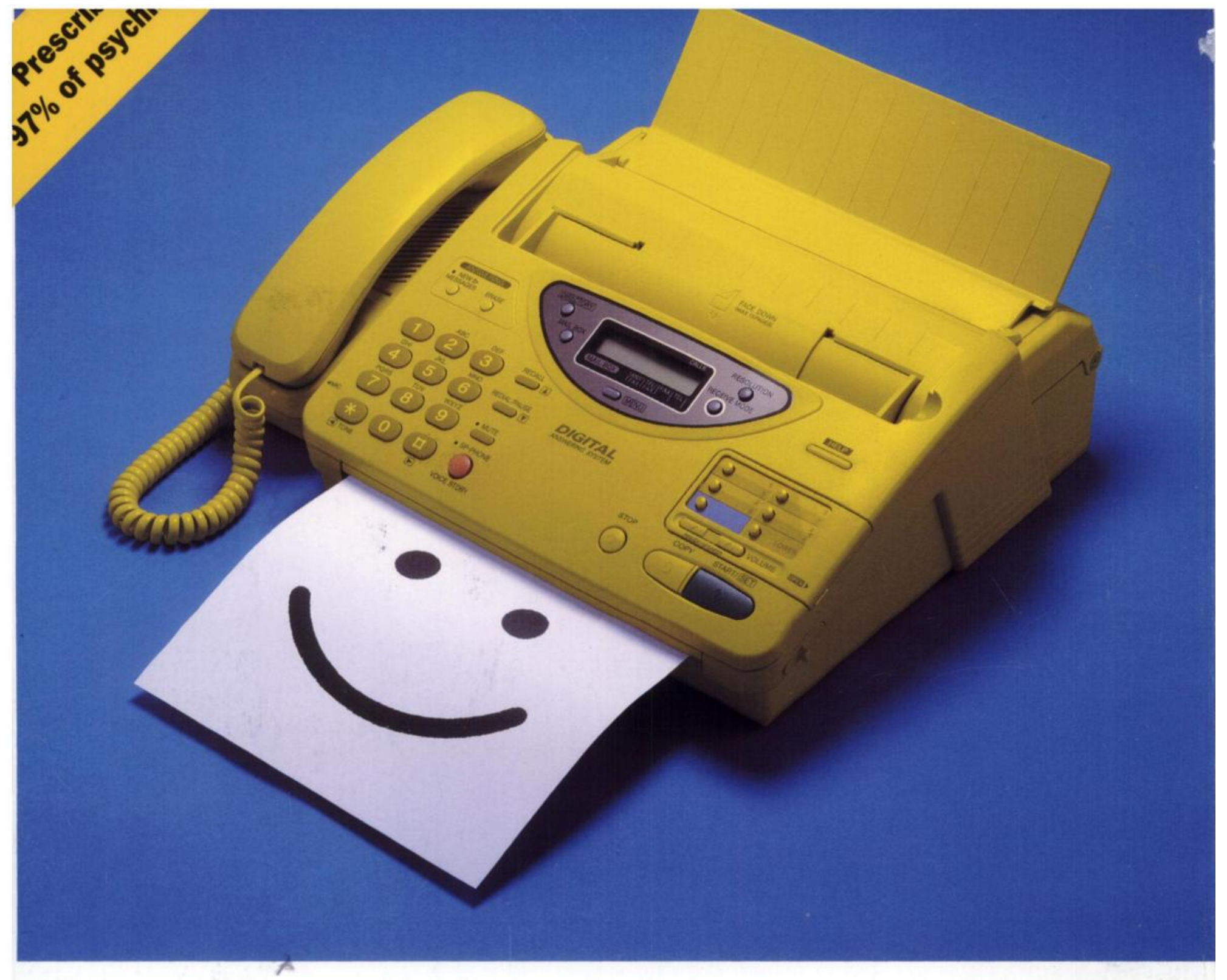

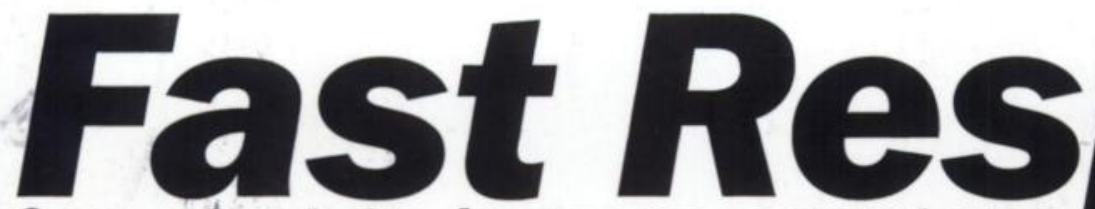

Can start to improve symptoms

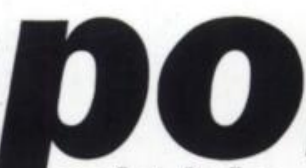

with in
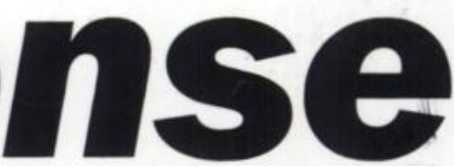

seven days PROPERT ON RACAL IBRAR? REDHCAL HOSPITA

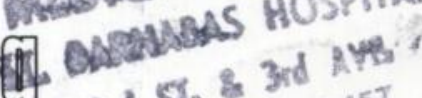

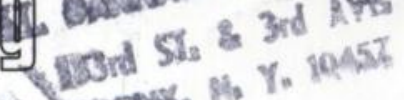
3.

\section{A first choice antidepressant}

\section{Stives

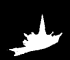 \\ CNS}

Aboreviated Prescribing Mnformation: Lustral (sertralino)

Presentation: Tablets"containing $50 \mathrm{mg}$ or $100 \mathrm{mg}$ sertraline. Indleations: Jreatment of symptoms of depres $s^{4} y e$ illness, including accompanying of depres
symptoms of illness, including accompanying recurrence of depressive episodes, including accompanying symptoms of anxiety. Dosace. Lustral should be given as a single daily dose. the initial dose is $50 \mathrm{mg}$ and the usual therapeutic dose is $50 \mathrm{mg}$ daily. Dosage can be further increased, if appropriate, to a maximum of $200 \mathrm{mg}$ daily. Patients should be maintained on the lowest effective dose and doses of $150 \mathrm{mg}$ or more should not be used for periods exceeding 8 weeks. Use in chillirem: Not recommended. Use in the eldinty. Usual adult dose. Contur

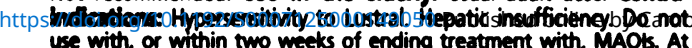

least 14 days should elapse before starting any MAOI following discontinuation of Lustral. Use duine prenency Lustral should be used only if dearly needed. Lectetions Not recommended. Precautions waminas: Renal insufficiency, unstable epilepsy, ECT, driving. Lustra should be discontinued in a patient who develops seizures. Lustral should not be administered to patients concurrenthy being treated with tranguillizers who drive or operate machinery. Patients should be dosety supervised for the possibility of suicide attempt or activation of maniamypomania. Druy interactions: Caution with other centrally active medication. Serotonergic duos induding tryptophan, sumatriptan and fenfluramine should not be used with lustral lithium levels should be monitored. Although Lustral has been shown to have no adverse interaction with alcohol, concomitant use with alcohol is not recommended. Interactions with other highly protein bound drugs should be borne in mind. The potential of Lustral to interact with e.g angartarinediazepamstolbutamide and cimetidine have not been fully assessed. With wartarin prothrombin time should be monitored when
Lustral is initiated or stopped. Side-Effects: Dry mouth, nausea, diarrhoea/loose stools, ejaculatory delay, tremor, increases sweating dyspepsia, dizziness, insomnia and somnolence. Rarefy. abnormal LFTs, hyponatraemia. Malaise and rash have been reported. seizures (see precautions, wamings). The following have been reported with Lustral but may have no causal relationship: wovement disorders, menstrual irregularities, hyperprolactinaemia and, galactorrhoea. As with all psychoactive medicines, possible side effects on discontinuation. Legal crterony. POM. Raic Mis cost $50 \mathrm{~ms}$ tablet (PL57/0308) Calendar pack of 28, $626.51 ; 100 \mathrm{mg}$ tablet (PL 57/0309) Calendar pack of 28, E39.77. Further information on request. Invicta ${ }^{\text {mW }}$ Pharmaceuticals or Richborough ${ }^{\text {Tw }}$ Pharmaceuticals Divisions of Pfizer Limited, Sandwich, Kent. Date of preparation: June 1997

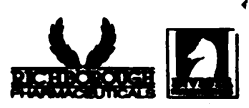




\section{The British Journal of Psychiatry}

INDEX TOVOLUME I7|

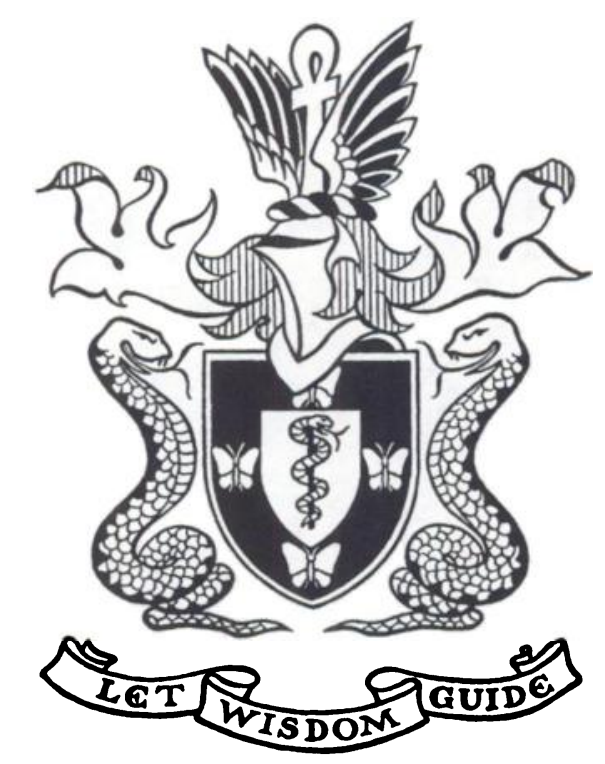

$$
\begin{gathered}
\text { JULY-DECEMBER } \\
1997
\end{gathered}
$$

(C) The Royal College of Psychiatrists 


\section{Compiled by Linda English}

PART I - SUBJECTS

PART II - CONTRIBUTORS

PART III - BOOK REVIEWS

\section{Abbreviation: C, correspondence}

\section{PART I. SUBJECTS}

Abnormal Involuntary Movements Scale

Poor memory, negative symptoms and abnormal movements in nevertreated patients with schizophrenia. R. G. McCreadie et al 360-363

Acamprosate

Efficacy and safety in the treatment of detoxified alcohol-dependent patients. I. Pelc et al 73-77

Admission rates

Social indicators and prediction of psychiatric admission in different Diagnostic groups. Anthony P. Boardman et al 457-462

\section{Adolescence}

Family functioning and life events in outcome of anorexia nervosa. Clive North et al 545-549

Long-term cannabis use and mental health. Wayne Hall \& Nadia Solowij (Editorial) 107-108

see also Childhood and adolescence

Affective disorders

Test of Xq26.3-28 linkage in bipolar and unipolar families. C. Smyth et al 578-581

see also Bipolar disorder, Depression, Dysthymia and Mania

\section{African-Caribbeans}

Increased rate of psychosis in Britain is not due to an excess of pregnancy and birth complications.

G. Hutchinson et al 145-147

\section{Ageing}

Eugeria, longevity and normal ageing. Karen Ritchie (Editorial) 501

Agranulocytosis

Eosinophilia, and clozapine. P. Bailey (C) 90. M. D. Adityanjee et al (C) $485-486$

\section{Alcohol misuse}

Comorbidity of mental disorders with substance misuse. Wayne Hall \& Michael Farrell (Editorial) 4-5.
Francis Keaney et al (C) 484-485

Dual diagnosis of severe mental illness and substance misuse: a case for specialist services? Sonia Johnson (Editorial) 205-208

Efficacy and safety of acamprosate in the treatment of detoxified patients. I. Pelc et al 73-77

Liver transplantation for alcoholic liver disease. Louise Howard \& Tom Fahy (Editorial) 497-500

Suicide and substance misuse. Jan Neeleman \& Michael Farrell (Editorial) 303-304

Alzheimer's disease

Clinical advances in degenerative dementias. Bruce L. Miller (Editorial) 1-3

Dementia with Lewy bodies. Neuropsychological and imaging differences. R. L. Allen et al (C) 486-487

Study of depression and anosognosia. Sergio E. Starkstein et al 47-52

Amisulpride

Low-dose neuroleptics in chronic schizophrenia. J. C. Speller et al 564-568

Analyses

Excess mortality of schizophrenia. Meta-analysis. Steve Brown (Review Article) 502-508

History of violent behaviour and schizophrenia. WHO study. Jan Volavka et al 9-14

Large same-year effects: fact or artefact? Edward L. Peterson \& Naomi Breslau (C) 487-488. Ronald C. Kessler (Author's reply) (C) 488

Publication trends of papers on schizophrenia. Analysis of three psychiatric journals. Massimo Morlino et al 452-456

Social indicators and prediction of psychiatric admission in different diagnostic groups. Anthony P. Boardmanet al 457-462

\section{3-16}

16-23

23-24
Anorexia nervosa

Family functioning and life events in the outcome in adolescents. Clive North et al 545-549

The overvalued idea. J. Treasure (C) 190

\section{Anosognosia}

Study of depression and anosognosia in Alzheimer's disease. Sergio E. Starkstein et al 47-52

\section{Antidepressants}

Cognitive therapy and pharmacotherapy in out-patients with recurrent depression. I.-M. Blackburn \& R. G. Moore 328-334

Cost-effectiveness of treatment. L. Head and V. O'Keane (C) 88

Suicide and cost-effectiveness. S. Lynch (C) 189

Treatment, outcome and predictors of response in elderly depressed inpatients. G. Pinner \& W. P. Bouman (C) 289. T. J. Heeren et al (Authors' reply) (C) 289-290

see also Selective serotonin reuptake inhibitors and Tricyclics

Antipsychotics

Establishing cost-effectiveness. David M. Taylor (C) 486. Clive E. Adams (C) 486

5- $\mathrm{HT}_{2 \mathrm{~A}}$ receptor occupancy in vivo and response to olanzapine and sertindole. M. J. Travis et al (C) 290-291

Subjective quality of life in schizophrenia. M. R. Agarwal (C) 392. M. Franz (Author's reply) (C) 392. S. Sengupta \& N. Kar (C) 587

see also Neuroleptics and individual names

Anxiety disorders

Brain blood flow. J. V. Lucey et al 346-350

Costs of community care for older people. Gill Livingston et al 56-59

Depression. In asylum-seekers. J. J. Rodenburg et al (C) 394 
Depressive disorders. Outcome in primary care. Clare Ronalds et al $427-433$

Eye movement desensitisation and reprocessing v. exposure in vivo for spider-phobic children. Peter Muris et al 82-86

Maternal stress or anxiety in pregnancy and emotional development of the child. Vivette Glover (Editorial) 105-106

Mental disorders among the community-dwelling elderly in Dublin. Michael Kirby et al 369-372

Arab culture

Postpartum psychiatric illness. R. Ghubash \& M. T. Abou-Saleh $65-68$

Beck Depression Inventory

Brain blood flow in anxiety disorders. J. V. Lucey et al 346-350

Brief cognitive therapy for major depressive disorder. Christine Scott et al 131-134

Bereitschaftpotentials

In schizophrenia. T. Karaman et al 31-34

Bipolar disorder

Lithium: balancing risks and benefits. John Cookson (Evidence-based psychiatry) 120-124

Lithium: evidence reconsidered. Joanna Moncrieff (Evidence-based psychiatry) 113-119

Test of Xq26.3-28 linkage in bipolar and unipolar families. C. Smyth et al 578-581

Tests of 'dissociation' and mood disorder. H. Merskey (C) 487

Black ethnic groups

Ethnic differences in satisfaction with mental health services. Sue Parkman et al 260-264

Ethnicity and use of acute psychiatric beds. Jonathan Koffman et al 238-241

GP recognition of psychological problems in a multi-ethnic innercity health district. S. M. Odell et al 537-541

Prejudice against providers of psychiatric services.

P. Harrison-Read (C) 582

Prevalence of dementia and depression among elderly people. C. F. M. McCracken et al 269-273

Psychosis and birth complications in African-Caribbeans in Britain.

G. Hutchinson et al 145-147

Blood monitoring

Clozapine, Chinese and blood.

S. A. Chong \& L. Chua (C) 89-90
Bonding disorder

"Anybody's child": severe disorders of mother-to-infant bonding.

R. Channi Kumar 175-181

Disorders of the mother-infant relationship. I. F. Brockington (C) 486

Borderline Syndrome Index

Therapeutic community treatment for severe personality disorder. Bridget Dolan et al 274-279

Bovine spongiform encephalopathy (BSE)

Human prion disease. J. G. Longhurst (C) 290

Brain

Bereitschaftpotential in schizophrenia. T. Karaman et al 31-34

Blood flow in anxiety disorders. J. V. Lucey et al 346-350

Grey matter correlates of syndromes in schizophrenia. David E. Rous (C) 484

$5-\mathrm{HT}_{2}$ receptor imaging in major depression: focal changes in orbitoinsular cortex. F. Biver et al 444-448

Injury. Psychological consequences of road traffic accidents in children and adolescents. D. Fearnley (C) 393. A. Di Gallo (Author's reply) (C) 393

Structural neuroimaging in learning disability. Shoumitro Deb (Review article) 417-419

see also Dopamine and 5-Hydroxytryptamine

Brazil

Multicentric study of psychiatric morbidity. Naomar Almeida-Filho et al 524-529

Brief Psychiatric Rating Scale

Randomised controlled trial of cognitive-behavioural therapy for psychosis

I: Elizabeth Kuipers et al 319-327

II: P. Garety et al 420-426

Sulpiride augmentation in schizophrenia partially responsive to clozapine. R. Shiloh et al 569-573

Britain

A very British kind of social psychiatry. Leon Eisenberg (Review Article, Michael Shepherd Memorial Symposium) 309-313

Increased rate of psychosis among African-Caribbeans is not due to an excess of pregnancy and birth complications. G. Hutchinson et al 145-147

see also East Anglia, Edinburgh, London, North Cheshire, Nottingham, Oxford and Royal Lunatic Asylum, Montrose

Burn victims

Psychological debriefing. Jonathan I. Bisson et al 78-81. G. Turnbull et al (C) 582. J. I. Bisson \& P. L. Jenkins (Authors' reply) (C) 583. R. P. Kraus (C) 583. David Reiss \& Morven Leese (C) 583-584

Camberwell Family Interview

Expressed emotion and depression. H. Hayhurst et al 439-443

Cannabis

Long-term use and mental health. Wayne Hall \& Nadia Solowij (Editorial) 107-108

Schizophrenia. J. G. Longhurst (C) 584. W. Hall (Author's reply) (C) 584-585

Childhood

Eye movement desensitisation and reprocessing v. exposure in vivo for spider phobia. Peter Muris et al 82-86

see also Infancy

\section{Childhood and adolescence}

Psychological consequences of road traffic accidents. D. Fearnley (C) 393. A. Di Gallo (Author's reply) (C) 393

Weight and shape concerns in girls. Peter J. Cooper \& Ian Goodyer 542-544

see also Adolescence

Chinese

Clozapine and blood. S. A. Chong \& L. Chua (C) 89-90

Tardive dyskinesia and CYP2D6 polymorphism. S.-A. Chong (C) 586

Chronic fatigue syndrome

Cognitive deficits in CFS, acute infective illness or depression. Ute Vollmer-Conna et al 377-381 Simon Wessely (Reading about) 92-93. R. Sykes (C) 393

\section{Citalopram}

Induced decreased libido. A. Michael \& J. J. Herrod (C) 90

Clapham rail accident

PTSD symptoms. Carolyn Selley et al 478-482

Clinical Anxiety Scale

Outcome of anxiety and depressive disorders in primary care. Clare Ronalds et al 427-433

\section{Clozapine}

Chinese and blood. S. A. Chong \& L. Chua (C) 89-90

Cost-effectiveness. UK clinic-based study. Katherine J. Aitchison \& Robert W. Kerwin 125-130.

R. W. Kerwin \& K. J. Aitchison (C) 584

Eosinophilia and agranulocytosis. P. Bailey (C) 90. M. D. Adityanjee et al (C) 485-486 
Establishing cost-effectiveness of atypical neuroleptics. Glenn Robert $\&$ Peter Kennedy (Editorial) 103-104

Induced hypersalivation. E. Szabadi (C) 89

Monotherapy and ketoacidosis. M. Pierides (C) 90-91

Pharmacokinetic interactions. David Taylor (Review Article) 109-112

Sulpiride augmentation in schizophrenia partially responsive to clozapine. R. Shiloh et al 569-573

Cochrane Library

Establishing cost-effectiveness of antipsychotics. Clive E. Adams (C) 486

Cognitive-behavioural therapy London-East Anglia randomised controlled trial for psychosis

I: Effects of treatment phase. Elizabeth Kuipers et al 319-327

II: Predictors of outcome. P. Garety et al 420-426

Cognitive impairment

Age-related cognitive decline and vision impairment affecting detection of dementia syndrome. Friedel M. Reischies \& Bernhard Geiselmann 449-451

Cognitive function and fall-related fractures. M. Jelicic \& G. I. J. M. Kempen (C) 88-89

Deficits in chronic fatigue syndrome, acute infective illness or depression. Ute Vollmer-Conna et al 377-381

Executive dysfunction and negative symptoms in schizophrenia: apparent gender differences in 'static' v. 'progressive' profiles. Paul J. Scully et al 154-158

Long-term cannabis use and mental health. Wayne Hall \& Nadia Solowij (Editorial) 107-108

Poor memory, negative symptoms and abnormal movements in never-treated Indian patients with schizophrenia. R. G. McCreadie et al 360-363

Subjective memory complaints in the elderly: depressive symptoms and future dementia. Ben Schmand et al 373-376

see also Dementia

Cognitive therapy

Brief therapy for major depressive disorder in primary care. Christine Scott et al 131-134

Pharmacotherapy. Controlled trial in out-patients with recurrent depression. I.-M. Blackburn \& R. G. Moore 328-334

Common mental disorders

In primary care in Harare, Zimbabwe. V. Patel et al 60-64

Community care

Costs for older people. Gill Livingston et al 56-59
Comorbidity

Clinical trials: severe mental illness and substance misuse. R. Laugharne (C) 587

Dual diagnosis of severe mental illness and substance misuse: a case for specialist services? Sonia Johnson (Editorial) 205-208

Large same-year effects: fact or artefact? Edward L. Peterson \& Naomi Breslau (C) 487-488. Ronald C. Kessler (Author's reply) (C) 488

Mental disorders among the community-dwelling elderly in Dublin. Michael Kirby et al 369-372

Mental disorders with substance misuse. Wayne Hall \& Michael Farrell (Editorial) 4-5. Francis Keaney et al (C) 484-485. I. H. A. Franken \& V. M. Hendriks (C) 485

Remission of transsexualism after comorbid OCD improved with self-exposure therapy. Isaac M. Marks \& David Mataix-Cols 389-390

Consultation-liaison

Psychiatry and medicine. Richard A. Mayou (Editorial) 203-204

Context of Illness Experience Interview Subjective experience of schizophrenia and depression. Janis Hunter Jenkins 20-25

Coping theory

Appraisal, psychological adjustment and $E E$ in relatives of patients suffering from schizophrenia. Christine Barrowclough \& Michael Parle 26-30

Corrigenda 190, 588

Costs

Community care for older people. Gill Livingston et al 56-59

Cost-effectiveness of antidepressant treatment. L. Head \& V. O'Keane (C) 88

Cost-effectiveness of clozapine. UK clinic-based study. Katherine J. Aitchison \& Robert W. Kerwin 125-130. R. W. Kerwin \& K. J. Aitchison (C) 584

Establishing cost-effectiveness of antipsychotics. David M. Taylor (C) 486. Clive E. Adams (C) 486

Establishing cost-effectiveness of atypical neuroleptics. Glenn Robert \& Peter Kennedy (Editorial) 103-104

Health economics. Paul McCrone \& Graham Thornicroft (Reading about) 191-193

Schizophrenia. Martin Knapp (Review Article) 509-518

Service provision for people with schizophrenia. I. Clinical and economic perspective. Fiona $\mathrm{H}$. Lang et al 159-164
Suicide and cost-effectiveness of antidepressants. S. Lynch (C) 189

Treating out-patients with schizophrenia in Nigeria. Toyin G. Suleiman et al 364-368

Crime

Violence, and schizophrenia. P. Noble (C) 189-190

Cultures

Clozapine, Chinese and blood. S. A. Chong \& L. Chua (C) 89-90

Common mental disorders in primary care in Harare, Zimbabwe. V. Patel et al 60-64

History of violent behaviour and schizophrenia. Jan Volavka et al 9-14

Postpartum psychiatric illness in Arab culture. R. Ghubash \& M. T. Abou-Saleh 65-68

Social course of schizophrenia. A. Cohen \& S. Lee (C) 287. T. Craig et al (Authors' reply) (C) 288

Subjective experience of schizophrenia and depression among US Latinos and EuroAmericans. Janis Hunter Jenkins 20-25

Cytochrome p450 system

Pharmacokinetic interactions involving clozapine. David Taylor (Review Article) 109-112

Tardive dyskinesia and CYP2D6 polymorphism in Chinese. S.-A. Chong (C) 586

Databases

Sigmund: European database of mental health surveys. C. Polge (C) 91

Deliberate self-harm

Cost-effectiveness of antidepressant treatment. L. Head \& V. O'Keane (C) 88

Trends in Oxford, 1985 to 1995. Keith Hawton et al 556-560

see also Suicide

Delusions

Depressive delusions and the general election. G. Yorston (C) 585

Randomised controlled trial of cognitive-behavioural therapy for psychosis, II. P. Garety et al 420-426

Dementia

Age-related cognitive decline and vision impairment affecting detection. Friedel M. Reischies \& Bernhard Geiselmann 449-451

Costs of community care for older people. Gill Livingston et al 56-59

Degenerative. Clinical advances. Bruce L. Miller (Editorial) 1-3

Depression and anosognosia in Alzheimer's disease. Sergio E. Starkstein et al 47-52 
Depression. Prevalence among elderly people in ethnic minorities.

C. F. M. McCracken et al 269-273

Mental disorders among the community-dwelling elderly in Dublin. Michael Kirby et al 369-372

Subjective memory complaints in the elderly: depressive symptoms and future dementia. Ben Schmand et al 373-376

With Lewy bodies and Alzheimer's disease. Neuropsychological and imaging differences. R. L. Allen et al (C) 486-487

\section{Depression \\ Aetiology \\ Adverse social circumstances in people of Pakistani origin in UK. Nusrat Husain et al 434-438 \\ Comorbidity \\ Large same-year effects: fact or artefact? Edward L. Peterson \& Naomi Breslau (C) 487-488. Ronald C. Kessler (Author's reply) (C) 488 \\ Complications \\ Study of depression and anosognosia in Alzheimer's disease. Sergio E. Starkstein et al 47-52 \\ Subjective memory complaints in the elderly: depressive symptoms and future dementia. Ben Schmand et al 373-376 \\ Course \\ Expressed emotion. H. Hayhurst et al 439-443 \\ Epidemiology \\ Anxiety and depression in asylum- seekers. J. J. Rodenburg et al (C) 394 \\ Mental disorders among the community-dwelling elderly in Dublin. Michael Kirby et al 369-372 \\ Prevalence among elderly people in ethnic minorities. \\ C. F. M. McCracken et al 269-273 \\ Genetics \\ Test of Xq26.3-28 linkage in bipolar and unipolar families. C. Smyth et al 578-581}

Outcome

In primary care. Clare Ronalds et al 427-433

Treatment, outcome and predictors of response in elderly in-patients. G. Pinner \& W. P. Bouman (C) 289. T. J. Heeren et al (Authors' reply) (C) 289-290

\section{Pathophysiology}

$5-\mathrm{HT}_{2}$ receptor imaging in major depression: focal changes in orbito-insular cortex. F. Biver et al 444-448

\section{Psychology}

Cognitive deficits in chronic fatigue syndrome, acute infective illness or depression. Ute Vollmer-

Conna et al 377-381

Delusions and the general election. G. Yorston (C) 585

Expressed emotion. H. Hayhurst et al 439-443

Subjective experience among US Latinos and Euro-Americans. Janis Hunter Jenkins 20-25

\section{Therapy}

Brief cognitive therapy for major depressive disorder in primary care. Christine Scott et al 131-134

Cognitive therapy and pharmacotherapy in out-patients with recurrent depression.

I.-M. Blackburn \& R. G. Moore 328-334

Costs of community care for older people. Gill Livingston et al 56-59

Lithium: evidence reconsidered. Joanna Moncrieff (Evidencebased psychiatry) 113-119. M. Bernadt \& G. Stein (C) 484

Outcome, and predictors of response in elderly in-patients. G. Pinner \& W. P. Bouman (C) 289. T. J. Heeren et al (Authors' reply) (C) 289-290

Plasma noradrenaline response to ECT. C. B. Kelly \& S. J. Cooper 182-186

see also Antidepressants and Puerperium

\section{Detoxification}

Two new methods of rapid intravenous detoxification in heroin addicts. Albert Seoane et al 340-345

Type of hospital setting and treatment outcome with heroin addicts. John Strang et al 335-339

Developing countries

Brazilian multicentric study of psychiatric morbidity. Naomar Almeida-Filho et al 524-529

Effects of level of socio-economic development on course of nonaffective psychosis. Vijoy K. Varma et al 256-259

Financial cost of treating out-patients with schizophrenia in Nigeria. Toyin G. Suleiman et al 364-368

History of violent behaviour and schizophrenia. Jan Volavka et al 9-14

Social course of schizophrenia.

A. Cohen \& S. Lee (C) 287.

T. Craig et al (Authors' reply) (C) 288

Diagnoses

Disability, outcome and case-mix in acute in-patient units. Brendon Boot et al 242-246
Dual diagnosis of severe mental illness and substance misuse. Sonia Johnson (Editorial) 205-208

Psychopathological syndromes and familial morbid risk of psychosis. A. Ryan (C) 289. J. Van Os et al (Authors' reply) (C) 289

Social indicators and prediction of psychiatric admission in different diagnostic groups. Anthony P. Boardmanet al 457-462

Tests of 'dissociation' and mood disorder. H. Merskey (C) 487

Disasters

PTSD symptoms and the Clapham rail accident. Carolyn Selley et al $478-482$

Dissociative disorder

Tests of 'dissociation' and mood disorder. H. Merskey (C) 487

Dopamine

Altered dopaminergic function and negative symptoms in schizophrenia. M. B. Knable et al 574-577

Dress styles

Psychiatrists and their patients: views on forms of dress and address. Julia A. Gledhill et al 228-232

Drivers

Suicides. Annakatri Ohberg et al 468-472

Drug misuse

Cannabis and schizophrenia. J. G. Longhurst (C) 584. W. Hall (Author's reply) (C) 584-585

Clinical trials: severe mental illness and substance misuse. R. Laugharne (C) 587

Comorbidity of mental disorders with substance misuse. Wayne Hall \& Michael Farrell (Editorial) 4-5. Francis Keaney et al (C) 484-485. I. H. A. Franken \& V. M. Hendriks (C) 485

Dual diagnosis of severe mental illness and substance misuse: a case for specialist services? Sonia Johnson (Editorial) 205-208

Long-term cannabis use and mental health. Wayne Hall \& Nadia Solowij (Editorial) 107-108

Suicide and substance misuse. Jan Neeleman \& Michael Farrell (Editorial) 303-304

Two new methods of rapid intravenous detoxification in heroin addicts. Albert Seoane et al 340-345

Type of hospital setting and treatment outcome with heroin addicts. John Strang et al 335-339

see also Alcohol misuse

Drugs

Comorbidity of mental disorders with substance misuse. Francis Keaney et al (C) 484-485 
Pharmacokinetic interactions involving clozapine. David Taylor (Review Article) 109-112

Use of seclusion, restraint, and emergency medication. H. Sequeira \& S. Halstead (C) 288-289

see also Acamprosate, Amisulpride, Antidepressants, Antipsychotics, Cannabis, Citalopram, Clozapine, d-Fenfluramine, Haloperidol, Heroin, Lithium, Neuroleptics, Olanzapine, Paracetamol, Paroxetine, Risperidone, Selective serotonin reuptake inhibitors, Sertindole, Sulpiride and Tricyclics

DSM-III

Brazilian multicentric study of psychiatric morbidity. Naomar Almeida-Filho et al 524-529

\section{DSM-III-R}

Age-related cognitive decline and vision impairment affecting detection of dementia syndrome. Friedel M. Reischies \& Bernhard Geiselmann 449-451

Brain blood flow in anxiety disorders. J. V. Lucey et al 346-350

Eye movement desensitisation and reprocessing v. exposure in vivo for spider-phobic children. Peter Muris et al 82-86

Outcome of anxiety and depressive disorders in primary care. Clare Ronalds et al 427-433

Plasma noradrenaline response to ECT in depressive illness.

C. B. Kelly \& S. J. Cooper 182-186

Subjective experience of schizophrenia and depression. Janis Hunter Jenkins 20-25

\section{DSM-IV}

Exposure and response prevention in OCD. Merran Lindsay et al 135-139

ICSD-90. Insomnia symptoms and sleep dissatisfaction. Maurice $M$. Ohayon et al 382-388

Late paraphrenia revisited. Robert Howard \& Peter Rabins (Editorial) 406-408

Dual diagnosis

Severe mental illness and substance misuse: a case for specialist services? Sonia Johnson (Editorial) 205-208

Dublin

Mental disorders among the community-dwelling elderly. Michael Kirby et al 369-372

Dutch Adult Reading Test

Subjective memory complaints in the elderly. Ben Schmand et al 373-376

\section{Dyskinesia}

Poor memory, negative symptoms and abnormal movements in nevertreated Indian patients with schizophrenia. R. G. McCreadie et al 360-363
Spontaneous dyskinesia in schizophrenic and nonschizophrenic patients. Wayne S. Fenton et al 265-268

see also Tardive dyskinesia

Dysthymia

Study of depression and anosognosia in Alzheimer's disease.

Sergio E. Starkstein et al 47-52

\section{East Anglia}

London. Randomised controlled trial of cognitive-behavioural therapy for psychosis

I: Elizabeth Kuipers et al 319-327

II: P. Garety et al 420-426

Eating disorders

Weight and shape concerns in girls. Peter J. Cooper \& Ian Goodyer 542-544

see also Anorexia nervosa

Economics see Costs

ECT see Electroconvulsive therapy

Edinburgh

Lunacy. Henry Rollin (One hundred years ago) 91

Edinburgh Postnatal Depression Scale Postnatal depression and elation among mothers and their partners. A. Lane et al 550-555

Postpartum psychiatric illness in Arab culture. R. Ghubash \&

M. T. Abou-Saleh 65-68

Elderly

Age-related cognitive decline and vision impairment affecting detection of dementia syndrome. Friedel M. Reischies \& Bernhard Geiselmann 449-451

Cognitive function and fall-related fractures. M. Jelicic \& G. I. J. M. Kempen (C) 88-89

Costs of community care. Gill Livingston et al 56-59

Eugeria, longevity and normal ageing. Karen Ritchie (Editorial) 501

Incidence and risk factors for severe tardive dyskinesia.

Michael P. Caligiuri et al 148-153

Late paraphrenia revisited. Robert Howard \& Peter Rabins (Editorial) 406-408

Mental disorders among the community-dwelling in Dublin. Michael Kirby et al 369-372

One hundred cases of attempted suicide. Jason Hepple \& Catherine Quinton 42-46

Prevalence of dementia and depression among people in ethnic minorities. C. F. M. McCracken et al 269-273

Seasonal changes in psychological wellbeing. John M. Eagles et al 53-55
Subjective memory complaints: depressive symptoms and future dementia. Ben Schmand et al 373-376

Treatment, outcome and predictors of response in depressed in-patients.

G. Pinner \& W. P. Bouman (C) 289.

T. J. Heeren et al (Authors' reply)

(C) 289-290

War pensions. M. Atkins \& S. Davies (C) $188-189$

Electroconvulsive therapy

Plasma noradrenaline response to ECT in depressive illness.

C. B. Kelly \& S. J. Cooper 182-186

Emergencies

Use of seclusion, restraint, and medication. $H$. Sequeira $\&$ S. Halstead (C) 288-289

Eosinophilia

Agranulocytosis, and clozapine. M. D. Adityanjee et al (C) 485-486

Agranulocytosis. Clozapine treatment. P. Bailey (C) 90

Epidemiology

Ethnicity in psychiatric epidemiology: need for precision. Swaran P. Singh (Editorial) 305-308

Sigmund: a European database of mental health surveys. C. Polge (C) 91

The evolving face of psychiatric epidemiology. Anthony Mann (Review Article, Michael Shepherd Memorial Symposium) 314-318

see also under Depression and Schizophrenia

Ethics

Family involvement in the care of people with psychoses. George I. Szmukler and Sidney Bloch (Editorial) 401-405

Ethnicity

Adverse social circumstances and depression in people of Pakistani origin in UK. Nusrat Husain et al 434-438

Determinants of GP recognition of psychological problems in a multiethnic inner-city health district. S. M. Odell et al 537-541

Increased rate of psychosis among African-Caribbeans in Britain is not due to an excess of pregnancy and birth complications. G. Hutchinson et al 145-147

In psychiatric epidemiology: need for precision. Swaran P. Singh (Editorial) 305-308

Integration between primary and secondary services in the care of the severely mentally ill: patients' and GPs' views. Jonathan Bindman et al 169-174

Prevalence of dementia and depression among elderly people.

C. F. M. McCracken et al 269-273 
Subjective experience of schizophrenia and depression among US Latinos and EuroAmericans. Janis Hunter Jenkins 20-25

Suicide by age, ethnic group, coroners' verdicts and country of birth. Jan Neeleman et al 463-467

see also Black ethnic groups and Chinese

Eugeria

Longevity and normal ageing. Karen Ritchie (Editorial) 501

Euro-Americans

Subjective experience of schizophrenia and depression. Janis Hunter Jenkins 20-25

Europe

Sigmund: database of mental health surveys. C. Polge (C) 91

Evidence-based psychiatry

Closing the gap between research and practice. John R. Geddes \& Paul J. Harrison 220-225. Invited commentaries. Ian Anderson et al 226-227. J. A. Powell \& J. R. Geddes (C) 586-587

Lithium: balancing risks and benefits. John Cookson 120-124

Lithium: evidence reconsidered. Joanna Moncrieff 113-119. M. Bernadt \& G. Stein (C) 484

Which evidence to believe? Sudip Sikdar (C) 483-484

Examinations

Mini Mental State Examination 373-376, 449-451

Present State Examination 65-68, 251-255

Exposure

Eye movement desensitisation and reprocessing $v$. exposure in vivo for spider-phobic children. Peter Muris et al 82-86

Remission of transsexualism after comorbid OCD improved with self-exposure therapy.

Isaac M. Marks \&

David Mataix-Cols 389-390

Response prevention. Controlled trial in OCD. Merran Lindsay et al 135-139

Expressed emotion (EE)

Appraisal, psychological adjustment and $E E$ in relatives of patients suffering from schizophrenia. Christine Barrowclough \& Michael Parle 26-30

Depression. H. Hayhurst et al 439-443

Eye movement desensitisation and reprocessing

v. exposure in vivo for spiderphobic children. Peter Muris et al 82-86
Fall-related fractures

Cognitive function. M. Jelicic \& G. I. J. M. Kempen (C) 88-89

Families

Appraisal, psychological adjustment and $E E$ in relatives of patients suffering from schizophrenia. Christine Barrowclough \& Michael Parle 26-30

Expressed emotion and depression. H. Hayhurst et al 439-443

Functioning and life events in outcome of adolescent anorexia nervosa. Clive North et al 545-549

Involvement in the care of people with psychoses. An ethical argument. George I. Szmukler \& Sidney Bloch (Editorial) 401-405

Test of Xq26.3-28 linkage in bipolar and unipolar families. C. Smyth et al 578-581

Family planning

Family planning needs and STD risk behaviours of female psychiatric out-patients. John H. Coverdale et al 69-72

Fathers

Postnatal depression and elation among mothers and their partners. A. Lane et al 550-555

d-Fenfluramine

Prolactin responses. Brain 5-HT function in OCD. N. A. Fineberg et al 280-282

Forms of address

Psychiatrists and their patients: views on forms of dress and address. Julia A. Gledhill et al 228-232

\section{Gender differences}

Age at onset of schizophrenia. L. E. DeLisi (C) 188

Brazilian multicentric study of psychiatric morbidity. Naomar Almeida-Filho et al 524-529

Executive dysfunction and negative symptoms in schizophrenia: apparent differences in 'static' $v$. 'progressive' profiles. Paul J. Scully et al 154-158

Minor psychiatric disorder in NHS trust staff. T. D. Wall et al 519-523

General election

Depressive delusions. G. Yorston (C) 585

\section{General Health Questionnaire}

GP recognition of psychological problems in a multi-ethnic innercity health district. S. M. Odell et al 537-541

Minor psychiatric disorder in NHS trust staff. T. D. Wall et al 519-523
Relatives of patients suffering from schizophrenia. Christine Barrowclough \& Michael Parle 26-30

Seasonal well-being in the elderly. John M. Eagles et al 53-55

\section{General practice}

Brief cognitive therapy for major depressive disorder in primary care. Christine Scott et al 131-134

Determinants of recognition of psychological problems in a multiethnic inner-city health district. S. M. Odell et al 537-541

Integration between primary and secondary services in the care of the severely mentally ill: patients' and GPs' views. Jonathan Bindman et al 169-174

Outcome of anxiety and depressive disorders in primary care. Clare Ronalds et al 427-433

Service provision for people with schizophrenia. II. Role of the GP. Fiona H. Lang et al 165-168. R. J. Simpson (C) 585. F. H. Lang (Author's reply) (C) 585-586

General psychiatry

In no-man's land. Martin Deahl and Trevor Turner (Editorial) 6-8. F. Souza Faria (C) 483

Genetics

Opportunities for psychiatry from findings. Michael Rutter \& Robert Plomin (Review Article) 209-219

Psychiatry. Michael J. Owen \& Peter McGuffin (Editorial) 201-202

Tardive dyskinesia and CYP2D6 polymorphism in Chinese. S.-A. Chong (C) 586

Test of Xq26.3-28 linkage in bipolar and unipolar families. C. Smyth et al 578-581

Geriatric Mental State (GMS)-AGECAT

Age-related cognitive decline and vision impairment affecting detection of dementia syndrome. Friedel M. Reischies \& Bernhard Geiselmann 449-451

Dementia and depression among elderly people in ethnic minorities. C. F. M. McCracken et al 269-273

Mental disorders among the community-dwelling elderly. Michael Kirby et al 369-372

One hundred cases of attempted suicide in the elderly. Jason Hepple \& Catherine Quinton 42-46

Subjective memory complaints in the elderly. Ben Schmand et al 373-376

Girls

Prevalence and significance of weight and shape concerns. Peter J. Cooper \& lan Goodyer 542-544 
Group homes

Clinical and social outcome of stay in small group homes for people with mental illness. Thomas Middelboe 251-255

Haloperidol

Low-dose neuroleptics in chronic schizophrenia. J. C. Speller et al 564-568

Hamilton Rating Scale for Depression

Brief cognitive therapy for major depressive disorder. Christine Scott et al 131-134

Expressed emotion and depression. H. Hayhurst et al 439-443

Outcome of anxiety and depressive disorders in primary care. Clare Ronalds et al 427-433

Sulpiride augmentation in schizophrenia partially responsive to clozapine. R. Shiloh et al 569-573

Head injury

Psychological consequences of road traffic accidents in children and adolescents. D. Fearnley (C) 393. A. Di Gallo (Author's reply) (C) 393

Health economics

Paul McCrone \& Graham Thornicroft (Reading about) 191-193

Health of the Nation Outcome Scales

Disability, outcome and case-mix in acute in-patient units. Brendon Boot et al 242-246

Health professionals

Helpfulness of interventions for mental disorders: beliefs compared with the general public. Anthony F. Jorm et al 233-237

Minor psychiatric disorder in NHS trust staff. T. D. Wall et al 519-523

Heroin

Two new methods of rapid intravenous detoxification in addicts previously treated without success. Albert Seoane et al 340-345

Type of hospital setting and treatment outcome with addicts. John Strang et al 335-339

Highs Scale

Postnatal depression and elation among mothers and their partners. A. Lane et al 550-555

History and Aetiology Schedule Age-related cognitive decline and vision impairment affecting detection of dementia syndrome. Friedel M. Reischies \& Bernhard Geiselmann 449-451
Hopelessness Scale

Care after attempted suicide.

Rob van der Sande et al 35-41

Hospitals

Lunacy in London and Edinburgh. Henry Rollin (One hundred years ago) 91

Royal Lunatic Asylum, Montrose. Henry Rollin (One hundred years ago) 190

Type of setting and treatment outcome with heroin addicts. John Strang et al 335-339

see also In-patients

Huntington's disease

Sleep disturbance. N. Taylor \& D. Bramble (C) 393

5-Hydroxytryptamine

Brain 5-HT function in OCD. N. A. Fineberg et al 280-282

$5-\mathrm{HT}_{2}$ receptor imaging in major depression. F. Biver et al 444-448

$5-\mathrm{HT}_{2 \mathrm{~A}}$ receptor occupancy in vivo and response to new antipsychotics. M. J. Travis et al (C) 290-291

Hypersalivation

Clozapine-induced. E. Szabadi (C) 89

ICD-9

Driver suicides. Annakatri Ohberg et al 468-472

ICD-10

Incidence of schizophrenia in Nottingham. J. Brewin et al 140-144

Late paraphrenia revisited. Robert Howard \& Peter Rabins (Editorial) 406-408

Impact of Events Scale

PTSD symptoms and the Clapham rail accident. Carolyn Selley et al $478-482$

India

Poor memory, negative symptoms and abnormal movements in nevertreated patients with schizophrenia. R. G. McCreadie et al 360-363

Infancy

"Anybody's child": severe disorders of mother-to-infant bonding.

R. Channi Kumar 175-181

Disorders of the mother-infant relationship. I. F. Brockington (C) 486

Maternal stress or anxiety in pregnancy and emotional development. Vivette Glover (Editorial) 105-106

Paroxetine withdrawal syndrome in a neonate. M. L. Dahl et al (C) 391-392

Influenza

Schizophrenia. T. J. Crow (C) 91
In-patients

Disability, outcome and case-mix in acute units. Brendon Boot et al 242-246

Elderly depressed. Treatment, outcome and predictors of response. G. Pinner \& W. P. Bouman (C) 289. T. J. Heeren et al (Authors' reply) (C) 289-290

Ethnicity and use of acute psychiatric beds. Jonathan Koffman et al 238-241

Intensive in-patient and community intervention $v$. routine care after attempted suicide. Rob van der Sande et al 35-41

Low-dose neuroleptics in chronic schizophrenia. J. C. Speller et al 564-568

One hundred suicides. France Proulx et al 247-250

Suicide among psychiatric in-patients. H. G. Morgan \& Ruth Stanton 561-563

Therapeutic community treatment for severe personality disorder. Bridget Dolan et al 274-279

see also Hospitals

Insomnia

DSM-IV and ICSD-90 symptoms and sleep dissatisfaction. Maurice $M$. Ohayon et al 382-388

International Classification of Sleep

Disorders (ICSD-90)

DSM-IV. Insomnia symptoms and sleep dissatisfaction. Maurice $M$. Ohayon et al 382-388

Interviews

Camberwell Family Interview 439-443

Context of Illness Experience Interview 20-25

Structured Clinical Interview for DSM-III-R Personality Disorders II 283-286

Ketoacidosis

Clozapine monotherapy. M. Pierides (C) $90-91$

Late paraphrenia

Revisited. Robert Howard \& Peter Rabins (Editorial) 406-408

Latinos

Subjective experience of schizophrenia and depression. Janis Hunter Jenkins 20-25

Learning disabilities

Structural neuroimaging. Shoumitro Deb (Review Article) 417-419

Use of seclusion, restraint, and emergency medication. H. Sequeira \& S. Halstead (C) 288-289 
Leeds Scale for Depression and Anxiety Seasonal well-being in the elderly. John M. Eagles et al 53-55

Leucopenia

Neutropenia. Risperidone-induced. Z. Dernovsek and R. Tavcar (C) 393-394

Lewy body dementia

Alzheimer's disease.

Neuropsychological and imaging differences. R. L. Allen et al (C) 486-487

Clinical advances in degenerative dementias. Bruce L. Miller (Editorial) 1-3

Life events

Family functioning and life events in outcome of adolescent anorexia nervosa. Clive North et al 545-549

Life Events and Difficulties Schedule

Adverse social circumstances and depression in people of Pakistani origin in UK. Nusrat Husain et al 434-438

Outcome of anxiety and depressive disorders in primary care. Clare Ronalds $e$ al $427-433$

\section{Lithium}

Balancing risks and benefits. John Cookson (Evidence-based psychiatry) 120-124

Evidence-based psychiatry: which evidence to believe? Sudip Sikdar (C) 483-484

Evidence reconsidered. Joanna Moncrieff (Evidence-based psychiatry) 113-119. M. Bernadt \& G. Stein (C) 484

Lethal poisoning with sustainedrelease preparations. M. Hrdlicka \& P. Sevcik (C) 586

Liver transplantation

For alcoholic liver disease. Louise Howard \& Tom Fahy (Editorial) 497-500

London

East Anglia. Randomised controlled trial of cognitive-behavioural therapy for psychosis

I: Elizabeth Kuipers et al 319-327

II: P. Garety et al 420-426

Ethnic differences in satisfaction with mental health services among people with psychosis in South London. Sue Parkman et al 260-264

Ethnicity and use of acute psychiatric eds: survey in North and South Thames regions. Jonathan Koffman et al 238-241

Lunacy. Henry Rollin (One hundred years ago) 91

PTSD symptoms and the Clapham rail accident. Carolyn Selley et al 478-482

Social networks, service use and psychosis in South London. Thomas Becker et al 15-19
Suicide by age, ethnic group, coroners' verdicts and country of birth. Jan Neeleman et al 463-467

\section{Longevity}

Eugeria, longevity and normal ageing. Karen Ritchie (Editorial) 501

Lunacy Act (1890)

Henry Rollin (One hundred years ago) 291-292, (One hundred years ago) 488-489

\section{Malingering}

Mark Turner (Editorial) 409-411

Mania

Lithium: balancing risks and benefits. John Cookson (Evidence-based psychiatry) 120-124

Lithium: evidence reconsidered. Joanna Moncrieff (Evidence-based psychiatry) 113-119

Postnatal depression and elation among mothers and their partners. A. Lane et al 550-555

Marital status

Gender and age at onset of schizophrenia. L. E. DeLisi (C) 188

\section{Medical Outcomes Trust Short Form} 36 (SF36)

Disability, outcome and case-mix in acute in-patient units. Brendon Boot et al 242-246

Medicine

Psychiatry, and consultation-liaison. Richard A. Mayou (Editorial) 203-204

Memory

Poor memory, negative symptoms and abnormal movements in nevertreated Indian patients with schizophrenia. R. G. McCreadie et al 360-363

Subjective complaints in the elderly: depressive symptoms and future dementia. Ben Schmand et al 373-376

Men

Suicide among psychiatric in-patients. H. G. Morgan \& Ruth Stanton 561-563

Trends in deliberate self-harm in Oxford. Keith Hawton et al556-560

see also Fathers and Gender differences

Mental health

Long-term cannabis use. Wayne Hall \& Nadia Solowij (Editorial) 107-108

Urban environment. Odd Steffen Dalgard \& Kristian Tambs 530-536

Mental health services

Clinical and social outcome of stay in small group homes. Thomas Middelboe 251-255
Comorbidity of mental disorders with substance misuse. Francis Keaney et al (C) 484-485

Costs of community care for older people. Gill Livingston et al 56-59

Dual diagnosis of severe mental illness and substance misuse: a case for specialist services? Sonia Johnson (Editorial) 205-208

Ethnic differences in satisfaction among people with psychosis in South London. Sue Parkman et al 260-264

Integration between primary and secondary services in the care of the severely mentally ill. Jonathan Bindman et al 169-174

Needs assessment for mentally disordered offenders. Andrea Cohen and Nigel Eastman (Review Article) 412-416

Prejudice against providers of services for Black people. P. Harrison-Read (C) 582

Provision for people with schizophrenia. Fiona $\mathrm{H}$. Lang et al

I. Clinical and economic perspective 159-164

II. Role of the GP 165-168. R. J. Simpson (C) 585 . F. H. Lang (Author's reply) (C) 585-586

Reports on psychotherapy commissioned by the NHS Executive. Anton Obholzer (Editorial) 495-496

Social networks and use among representative cases of psychosis in South London. Thomas Becker et al 15-19

Trends in deliberate self-harm in Oxford. Implications for clinical services and prevention of suicide. Keith Hawton et al 556-560

see also General practice, Hospitals and In-patients

Mental health surveys

Sigmund: a European database. C. Polge (C) 91

Mental illness see Psychiatric disorders

Mentally disordered offenders see Offenders

Mini Mental State Examination

Age-related cognitive decline and vision impairment affecting detection of dementia syndrome. Friedel M. Reischies \& Bernhard Geiselmann 449-451

Subjective memory complaints in the elderly. Ben Schmand et al 373-376

Mood disorders see Affective disorders

Morbidity

Brazilian multicentric study of psychiatric morbidity. Naomar Almeida-Filho et al 524-529 
Mortality

Excess mortality of schizophrenia. Steve Brown (Review Article) 502-508

Lethal lithium poisoning with sustained-release preparations. M. Hrdlicka \& P. Sevcik (C) 586

Long-term mortality after first psychiatric admission. V. Hansen (C) 187. C. Stark et al (C) 187. A. S. Lee et al (Authors' reply) (C) 187-188

see also Suicide

Moscow

The Moscow meeting. Henry Rollin (One hundred years ago) 394

Mother-to-infant bonding

"Anybody's child": severe disorders of bonding. R. Channi Kumar 175-181. I. F. Brockington (C) 486

Movement disorders

Bereitschaftpotential in schizophrenia. T. Karaman et al 31-34

Poor memory, negative symptoms and abnormal movements in nevertreated Indian patients with schizophrenia. R. G. McCreadie et al 360-363

Spontaneous dyskinesia in schizophrenic and nonschizophrenic patients. Wayne S. Fenton et al 265-268 see also Tardive dyskinesia

National Confidential Inquiry into Suicide and Homicide by People with Mental Illness L. Appleby et al (C) 391

National Health Service Minor psychiatric disorder in NHS trust staff. T. D. Wall et al 519-523

National Health Service Executive Reports on psychotherapy commissioned by the NHS Executive. Anton Obholzer (Editorial) 495-496

Needs assessment

For mentally disordered offenders. Andrea Cohen \& Nigel Eastman (Review Article) 412-416

Neuroleptics

Atypical. Establishing costeffectiveness. Glenn Robert \& Peter Kennedy (Editorial) 103-104

Risk factors for severe tardive dyskinesia in older patients. Michael P. Caligiuri et al 148-153

Study of in-patients with chronic schizophrenia characterised by persistent negative symptoms. J. C. Speller et al 564-568

see also Antipsychotics and individual names
Neutropenia

Leucopenia. Risperidone-induced. Z. Dernovsek and R. Tavcar (C) 393-394

Nigeria

Financial cost of treating out-patients with schizophrenia.

Toyin G. Suleiman et al 364-368

Noradrenaline

Plasma noradrenaline response to ECT in depressive illness. C. B. Kelly \& S. J. Cooper 182-186

North Cheshire

Weather conditions and fatal selfharm. Emad Salib \& Nicola Gray 473-477

Nottingham

Incidence of schizophrenia. J. Brewin et al 140-144

Number needed to detain

S. Fleminger (C) 287

Obsessive-compulsive disorder (OCD)

Brain blood flow in anxiety disorders. J. V. Lucey et al 346-350

Brain 5-HT function. N. A. Fineberg et al 280-282

Controlled trial of exposure and response prevention. Merran Lindsay et al 135-139

Remission of transsexualism after comorbid OCD improved with self-exposure therapy.

Isaac M. Marks \&

David Mataix-Cols 389-390

Offenders

Crime, violence, and schizophrenia. P. Noble (C) 189-190

Needs assessment. Andrea Cohen $\&$ Nigel Eastman (Review Article) 412-416

Number needed to detain. S. Fleminger (C) 287

\section{Olanzapine}

$5-\mathrm{HT}_{2 \mathrm{~A}}$ receptor occupancy in vivo and response to new antipsychotics. M. J. Travis et al (C) 290-291

Old age see Elderly

One bundred years ago

Henry Rollin

Lunacy in London and Edinburgh 91

Mental disease out-patients 587-588

Royal Lunatic Asylum, Montrose 190

The Lunacy Act, 1890, and its amendments 291-292, 488-489

The Moscow meeting 394

Orbito-insular cortex

$5-\mathrm{HT}_{2}$ receptor imaging in major depression: focal changes. F. Biver et al 444-448
Out-patients

Cognitive therapy and pharmacotherapy in recurrent depression. I.-M. Blackburn \& R. G. Moore 328-334

Family planning needs and STD risk behaviours of female psychiatric out-patients. John H. Coverdale et al 69-72

Financial cost of treating out-patients with schizophrenia in Nigeria.

Toyin G. Suleiman et al 364-368

Mental disease out-patients. Henry Rollin (One hundred years ago) 587-588

Overdose see Deliberate self-harm

Oxford

Trends in deliberate self-harm, 1985 to 1995. Keith Hawton et al $556-560$

Pakistani immigrants

Adverse social circumstances and depression in UK. Nusrat Husain et al 434-438

Panic disorder with agoraphobia Brain blood flow in anxiety disorders. J. V. Lucey et al 346-350

Paracetamol

Trends in deliberate self-harm in Oxford. Keith Hawton et al 556-560

Paroxetine

Withdrawal syndrome in a neonate. M. L. Dahl et al (C) 391-392

Patients

Family planning needs and STD risk behaviours of female psychiatric out-patients. John H. Coverdale et al 69-72

Integration between primary and secondary services in the care of the severely mentally ill: patients' and GPs' views. Jonathan Bindman et al 169-174

Listening to them. Linda Gask (Editorial) 301-302

Psychiatrists and their patients: views on forms of dress and address. Julia A. Gledhill et al 228-232

Subjective experience of schizophrenia and depression among US Latinos and EuroAmericans. Janis Hunter Jenkins 20-25

Personal accounts

Listening to patients. Linda Gask (Editorial) 301-302

Personal Health Questionnaire

Adverse social circumstances and depression in people of Pakistani origin in UK. Nusrat Husain et al 434-438 
Personality disorder

Psychopathology. Tourette's

syndrome. Mary M. Robertson et al 283-286

Severe. Change in borderline symptoms one year after therapeutic community treatment. Bridget Dolan et al 274-279

Pharmacotherapy see Drugs

Phobias

Eye movement desensitisation and reprocessing v. exposure in vivo for spider-phobic children. Peter Muris et al 82-86

Positive and Negative Syndrome Scale

Poor memory, negative symptoms and abnormal movements in nevertreated patients with schizophrenia. R. G. McCreadie et al 360-363

Positron emission tomography

$5-\mathrm{HT}_{2}$ receptor imaging in major depression: focal changes in orbitoinsular cortex. F. Biver et al 444-448

Post-traumatic stress disorder

Brain blood flow in anxiety disorders. J. V. Lucey et al 346-350

Psychological consequences of road traffic accidents in children and adolescents. D. Fearnley (C) 393. A. Di Gallo (Author's reply) (C) 393

Psychological debriefing for victims of acute burn trauma. Jonathan I. Bisson et al 78-81

Symptoms and the Clapham rail accident. Carolyn Selley et al $478-482$

Pregnancy

Family planning needs and STD risk behaviours of female psychiatric out-patients. John H. Coverdale et al 69-72

Increased rate of psychosis among African-Caribbeans in Britain is not due to an excess of pregnancy and birth complications. G. Hutchinson et al 145-147

Maternal stress or anxiety and emotional development of the child. Vivette Glover (Editorial) 105-106

Present State Examination

Clinical and social outcome of stay in small group homes. Thomas Middelboe 251-255

Postpartum psychiatric illness in Arab culture. R. Ghubash \&

M. T. Abou-Saleh 65-68

Prevention

Strategies for preventing suicide. Glyn Lewis et al 351-354

Trends in deliberate self-harm in Oxford. Implications for clinical services and prevention of suicide. Keith Hawton et al 556-560

Primary care see General practice
Prion diseases

BSE and human prion disease.

J. G. Longhurst (C) 290

PRiSM Study 4

Ethnic differences in satisfaction with mental health services among people with psychosis in South London. Sue Parkman et al 260-264

Psychiatric Assessment Schedule

Adverse social circumstances and depression in people of Pakistani origin in UK. Nusrat Husain et al 434-438

Outcome of anxiety and depressive disorders in primary care. Clare Ronalds et al 427-433

Psychiatric disorders

Among the community-dwelling elderly in Dublin. Michael Kirby et al 369-372

Brazilian multicentric study of morbidity. Naomar Almeida-Filho et al 524-529

Clinical and social outcome of stay in small group homes. Thomas Middelboe 251-255

Clinical trials: severe mental illness and substance misuse. $R$. Laugharne (C) 587

Common mental disorders in primary care in Harare, Zimbabwe. V. Patel et al 60-64

Comorbidity with substance misuse. Wayne Hall \& Michael Farrell (Editorial) 4-5. Francis Keaney et al (C) 484-485. I. H. A. Franken \& V. M. Hendriks (C) 485

Determinants of GP recognition in a multi-ethnic inner-city health district. S. M. Odell et al 537-541

Dual diagnosis of severe mental illness and substance misuse. Sonia Johnson (Editorial) 205-208

Helpfulness of interventions: beliefs of health professionals compared with the general public. Anthony F. Jorm et al 233-237

Integration between primary and secondary services in the care of the severely mentally ill. Jonathan Bindman et al 169-174

Long-term mortality after first psychiatric admission. V. Hansen (C) 187. C. Stark et al (C) 187. A. S. Lee et al (Authors' reply) (C) 187-188

Lunacy in London and Edinburgh. Henry Rollin (One hundred years ago) 91

Mental disease out-patients. Henry Rollin (One hundred years ago) 587-588

Minor disorder in NHS trust staff. T. D. Wall et al 519-523

National Confidential Inquiry into Suicide and Homicide by People with Mental Illness. L. Appleby et al (C) 391
Psychiatric journals

Publication trends of papers on schizophrenia. Analysis of three journals. Massimo Morlino et al $452-456$

Psychiatrists

Their patients: views on forms of dress and address. Julia A. Gledhill et al 228-232

Psychiatry

Genetics. Michael J. Owen \& Peter McGuffin (Editorial) 201-202

Medicine, and consultation-liaison. Richard A. Mayou (Editorial) 203-204

Opportunities from genetic findings. Michael Rutter \& Robert Plomin (Review Article) 209-219

The Church. P. Daborn (C) 391

Transcending barriers between it and religion. D. Roberts (C) 188

Psychological debriefing

For victims of acute burn trauma. Jonathan I. Bisson et al 78-81. G. Turnbull et al (C) 582 . J. I. Bisson \& P. L. Jenkins (Authors' reply) (C) 583. R. P. Kraus (C) 583. David Reiss \& Morven Leese (C) 583-584

Psychosis

Dual diagnosis of severe mental illness and substance misuse. Sonia Johnson (Editorial) 205-208

Effects of level of socio-economic development on course of nonaffective psychosis. Vijoy K. Varma et al 256-259

Ethnic differences in satisfaction with mental health services in South London. Sue Parkman et al 260-264

Family involvement in care. An ethical argument. George I. Szmukler \& Sidney Bloch (Editorial) 401-405

Increased rate among AfricanCaribbeans in Britain is not due to an excess of pregnancy and birth complications. G. Hutchinson et al 145-147

London-East Anglia randomised controlled trial of cognitivebehavioural therapy

I: Effects of treatment phase. Elizabeth Kuipers et al 319-327

II: Predictors of outcome.

P. Garety et al 420-426

Long-term cannabis use and mental health. Wayne Hall \& Nadia Solowij (Editorial) 107-108

Psychopathological syndromes and familial morbid risk. A. Ryan (C) 289. J. Van Os et al (Authors' reply) (C) 289

Social networks and service use among representative cases in South London. Thomas Becker et al 15-19 
Psychotherapy

Reports commissioned by the NHS Executive. Anton Obholzer (Editorial) 495-496

Therapeutic community treatment for severe personality disorder. Bridget Dolan et al 274-279

see also Cognitive-behavioural therapy, Cognitive therapy and Psychological debriefing

PTSD see Post-traumatic stress disorder

Public attitudes

Helpfulness of interventions for mental disorders. Anthony F. Jorm et al 233-237

Puerperium

Postnatal depression and elation among mothers and their partners. A. Lane et al 550-555

Postpartum psychiatric illness in Arab culture. R. Ghubash \& M. T. Abou-Saleh 65-68

Severe disorders of mother-to-infant bonding. R. Channi Kumar 175-181. I. F. Brockington (C) 486

Quality of life

Subjective quality of life and drug treatment for schizophrenia. S. Sengupta and N. Kar (C) 587

Subjective quality of life in schizophrenia. M. R. Agarwal (C) 392. M. Franz (Author's reply) (C) 392

Questionnaires

General Health Questionnaire 26-30, 53-55, 519-523, 537-541

Personal Health Questionnaire 434-438

Self Report Questionnaire 65-68

Rating scales see Scales

Refugees

Anxiety and depression in asylumseekers. J. J. Rodenburg et al (C) 394

Relatives see Families

Religion

Psychiatry and the Church. P. Daborn (C) 391

Transcending barriers between it and psychiatry. D. Roberts (C) 188

Research

Closing the gap between research and practice. John R. Geddes \& Paul J. Harrison (Evidence-based psychiatry) 220-225. Invited commentaries. Ian Anderson et al (Evidence-based psychiatry) 226-227
Publication trends of papers on schizophrenia. Analysis of three psychiatric journals. Massimo Morlino et al 452-456

Research Diagnostic Criteria

Expressed emotion and depression. H. Hayhurst et al 439-443

Risk assessment

Clinical risk management. C. Jones (C) 290

Number needed to detain. S. Fleminger (C) 287

Suicide among psychiatric in-patients. H. G. Morgan \& Ruth Stanton 561-563

Risperidone

Establishing cost-effectiveness of atypical neuroleptics. Glenn Robert \& Peter Kennedy (Editorial) 103-104

Induced leucopenia and neutropenia. Z. Dernovsek \& R. Tavcar (C) 393-394

Road traffic accidents

Driver suicides. Annakatri Ohberg et al 468-472

Psychological consequences in children and adolescents. D. Fearnley (C) 393. A. Di Gallo (Author's reply) (C) 393

Royal Lunatic Asylum, Montrose Henry Rollin (One hundred years ago) 190

Rural populations

Effects of level of socio-economic development on course of nonaffective psychosis. Vijoy K. Varma et al 256-259

Scales

Abnormal Involuntary Movements Scale 360-363

Brief Psychiatric Rating Scale 319-327, 420-426, 569-573

Clinical Anxiety Scale 427-433

Edinburgh Postnatal Depression Scale 65-68, 550-555

Hamilton Rating Scale for Depression 131-134, 427-433, 439-443, 569-573

Health of the Nation Outcome Scales 242-246

Highs Scale 550-555

Hopelessness Scale 35-41

Impact of Events Scale 478-482

Leeds Scale for Depression and Anxiety 53-55

Positive and Negative Syndrome Scale 360-363

Scale for the Assessment of Negative Symptoms 569-573

Scale for the Assessment of Positive Symptoms 569-573
Wang Scale 340-345

Wechsler Memory Scale 360-363

see also Beck Depression Inventory, Borderline Syndrome Index, Examinations, Geriatric Mental State (GMS)-AGECAT, Interviews, Medical Outcomes Trust Short Form 36, Questionnaires, Research Diagnostic Criteria, Schedules, Symptom Checklist and Tests

Schedules

History and Aetiology Schedule 449-451

Life Events and Difficulties Schedule 427-433, 434-438

Psychiatric Assessment Schedule 427-433, 434-438

Schedule for Affective Disorders and Schizophrenia 20-25

Verona Service Satisfaction Schedule 260-264

Schizoaffective disorder

Psychopathological syndromes and familial morbid risk of psychosis. A. Ryan (C) 289. J. Van Os et al (Authors' reply) (C) 289

Schizophrenia

Aetiology

Cannabis. J. G. Longhurst (C) 584. W. Hall (Author's reply) (C) 584-585

Gender and age at onset. L. E. DeLisi (C) 188

Influenza. T. J. Crow (C) 91

Complications

Crime and violence. P. Noble (C) 189-190

Excess mortality. Steve Brown (Review Article) 502-508

History of violent behaviour in different cultures. Jan Volavka et al 9-14

Poor memory, negative symptoms and abnormal movements in never-treated Indian patients. R. G. McCreadie et al 360-363

Risk factors for suicide in patients. C. D. Rossau \& P. B. Mortensen 355-359

Spontaneous dyskinesia in schizophrenic and nonschizophrenic patients. Wayne S. Fenton et al 265-268

Course

Effects of level of socio-economic development on course of nonaffective psychosis. Vijoy $\mathrm{K}$. Varma et al 256-259

Executive dysfunction and negative symptoms: apparent gender differences in 'static' $v$. 'progressive' profiles. Paul J. Scully et al 154-158

Social course. A. Cohen \& S. Lee (C) 287. T. Craig et al (Authors' reply) (C) 288 
Epidemiology

Incidence in Nottingham. J. Brewin et al 140-144

Pathology

Grey matter correlates of syndromes. David E. Rous (C) 484

Pathophysiology

Altered dopaminergic function and negative symptoms in drug-free patients. M. B. Knable et al 574-577

Bereitschaftpotential. T. Karaman et al 31-34

Psychology

Appraisal, psychological adjustment and $E E$ in relatives of patients. Christine Barrowclough \& Michael Parle 26-30

Poor memory, negative symptoms and abnormal movements in never-treated Indian patients. R. G. McCreadie et al 360-363

Subjective experience among US Latinos and Euro-Americans. Janis Hunter Jenkins 20-25

Research

Publication trends of papers. Analysis of three psychiatric journals. Massimo Morlino et al 452-456

Therapy

Cost-effectiveness of clozapine. UK clinic-based study. Katherine J. Aitchison and Robert W. Kerwin 125-130

Costs. Martin Knapp (Review Article) 509-518

Financial cost of treating outpatients in Nigeria. Toyin G. Suleiman et al 364-368

Neuroleptic study of chronic inpatients characterised by persistent negative symptoms. J. C. Speller et al 564-568

Service provision. Fiona $\mathrm{H}$. Lang et al

I. Clinical and economic perspective 159-164

II. Role of the GP 165-168. R. J. Simpson (C) 585. F. H. Lang (Author's reply) (C) 585-586

Subjective quality of life and drug treatment. S. Sengupta $\&$ N. Kar (C) 587

Subjective quality of life. M. R. Agarwal (C) 392. M. Franz (Author's reply) (C) 392

Sulpiride augmentation in people partially responsive to clozapine. R. Shiloh et al 569-573

Screening Test for Co-Morbid

Personality Disorders

Personality disorder in Tourette's syndrome. Mary M. Robertson et al 283-286

Seasonality

Changes in psychological well-being in an elderly population.

John M. Eagles et al 53-55
Seclusion

Restraint, and emergency medication. H. Sequeira and S. Halstead (C) 288-289

Selective serotonin reuptake inhibitors

Cost-effectiveness of antidepressant treatment. L. Head \& V. O'Keane (C) 88

Discontinuation rates of SSRIs and tricyclics. I. Anderson \& C. Mortimore (C) 87. S. Lynch \& S. Curran (C) 87. M. Hotopf et al (Authors' reply) (C) 87-88

Suicide and cost-effectiveness of antidepressants. S. Lynch (C) 189

see also Citalopram and Paroxetine

Self Report Questionnaire

Postpartum psychiatric illness in Arab culture. R. Ghubash \& M. T. Abou-Saleh 65-68

Serotonin see 5-Hydroxytryptamine

Sertindole

$5-\mathrm{HT}_{2 \mathrm{~A}}$ receptor occupancy in vivo and response to new antipsychotics. M. J. Travis et al (C) 290-291

Sex differences see Gender differences

Sexual disorders

Remission of transsexualism after comorbid OCD improved with self-exposure therapy.

Isaac M. Marks \&

David Mataix-Cols 389-390

Sexual dysfunction

Citalopram-induced decreased libido. A. Michael \& J. J. Herrod (C) 90

Sexually transmitted diseases

Family planning needs and risk behaviours of female psychiatric out-patients. John H. Coverdale et al 69-72

Sigmund

European database of mental health surveys. C. Polge (C) 91

Single photon emission computed tomography Dopaminergic function and negative symptoms in schizophrenia. M. B. Knable et al 574-577

Single photon emission tomography Brain blood flow in anxiety disorders. J. V. Lucey et al 346-350

Sleep disorders

DSM-IV and ICSD-90 insomnia symptoms and sleep dissatisfaction. Maurice M. Ohayon et al 382-388

Sleep disturbance and Huntington's disease. N. Taylor \& D. Bramble (C) 393

Social factors

Adverse social circumstances and depression in people of Pakistani origin in UK. Nusrat Husain et al 434-438
Outcome of anxiety and depressive disorders in primary care. Clare Ronalds et al 427-433

Prediction of psychiatric admission in different diagnostic groups.

Anthony P. Boardman et al 457-462

Social networks and service use among representative cases of psychosis in South London. Thomas Becker et al 15-19

Urban environment and mental health. Odd Steffen Dalgard \& Kristian Tambs 530-536

Social psychiatry

A very British kind of social psychiatry. Leon Eisenberg (Review Article, Michael Shepherd Memorial Symposium) 309-313

Socio-economic development

Effects on course of non-affective psychosis. Vijoy K. Varma et al 256-259

Somatic symptoms

Adverse social circumstances and depression in people of Pakistani origin in UK. Nusrat Husain et al 434-438

Spider phobia

Eye movement desensitisation and reprocessing v. exposure in vivo for children. Peter Muris et al 82-86

SSRIs see Selective serotonin reuptake inhibitors

Stress

Maternal stress or anxiety in pregnancy and emotional development of the child. Vivette Glover (Editorial) 105-106

Structural neuroimaging

In learning disability. Shoumitro Deb (Review Article) 417-419

Structured Clinical Interview for DSM-III-R Personality Disorders II Personality disorder in Tourette's syndrome. Mary M. Robertson et al 283-286

Subjective experience

Listening to patients. Linda Gask (Editorial) 301-302

Schizophrenia and depression among US Latinos and Euro-Americans. Janis Hunter Jenkins 20-25

Substance misuse see Alcohol and Drug misuse

Suicide

Among psychiatric in-patients. H. G. Morgan \& Ruth Stanton 561-563

By age, ethnic group, coroners' verdicts and country of birth. Jan Neeleman et al 463-467

Cost-effectiveness of antidepressants. S. Lynch (C) 189

Drivers. Annakatri Ohberget al 468-472

Excess mortality of schizophrenia. Steve Brown (Review Article) 502-508 
Intensive in-patient and community intervention $v$. routine care after attempted suicide. Rob van der Sande et al 35-41

Long-term mortality after first psychiatric admission. V. Hansen (C) 187. C. Stark et al (C) 187. A. S. Lee et al (Authors' reply) (C) 187-188

National Confidential Inquiry into Suicide and Homicide by People with Mental Illness. L. Appleby et al (C) 391

One hundred cases of attempted suicide in the elderly. Jason Hepple \& Catherine Quinton 42-46

One hundred in-patient suicides. France Proulx et al 247-250

Risk factors in patients with schizophrenia. C. D. Rossau \& P. B. Mortensen 355-359

Strategies for prevention. Glyn Lewis et al 351-354

Substance misuse. Jan Neeleman \& Michael Farrell (Editorial) 303-304

Trends in deliberate self-harm in Oxford. Implications for clinical services and prevention of suicide. Keith Hawton et al 556-560

Weather conditions and fatal selfharm in North Cheshire. Emad Salib \& Nicola Gray 473-477

Sulpiride

Augmentation in schizophrenia partially responsive to clozapine. R. Shiloh et al 569-573

Symptom Checklist (SCL-90)

Care after attempted suicide. Rob van der Sande et al 35-41

Comorbidity of mental disorders with substance misuse. I. H. A. Franken \& V. M. Hendriks (C) 485

Symptoms

Change in borderline symptoms after therapeutic community treatment for severe personality disorder. Bridget Dolan et al 274-279

Dopaminergic function and negative symptoms in schizophrenia. M. B. Knable et al 574-577

DSM-IV and ICSD-90 insomnia symptoms and sleep dissatisfaction. Maurice M. Ohayon et al 382-388

Executive dysfunction and negative symptoms in schizophrenia. Paul J. Scully et al 154-158

Low-dose neuroleptics in chronic schizophrenia characterised by persistent negative symptoms. J. C. Speller et al 564-568

Malingering. Mark Turner (Editorial) 409-411

Poor memory, negative symptoms and abnormal movements in nevertreated patients with schizophrenia. R. G. McCreadie et al 360-363

PTSD symptoms and the Clapham rail accident. Carolyn Selley et al $478-482$
Somatic. Adverse social circumstances and depression in people of Pakistani origin in UK. Nusrat Husain et al 434-438

Syndromes

Grey matter correlates of syndromes in schizophrenia. David E. Rous (C) 484

Psychopathological syndromes and familial morbid risk of psychosis. A. Ryan (C) 289. J. Van Os et al (Authors' reply) (C) 289

see also Chronic fatigue, Tourette's and Withdrawal

Tardive dyskinesia CYP2D6 polymorphism in Chinese. S.-A. Chong (C) 586

Severe. Incidence and risk factors in older patients. Michael P. Caligiuri et al 148-153

Tests

Dutch Adult Reading Test 373-376

Screening Test for Co-Morbid Personality Disorders 283-286

Therapeutic community treatment

For severe personality disorder. Bridget Dolan et al 274-279

Tourette's syndrome

Personality disorder and psychopathology. Mary M. Robertson et al 283-286

Toxicity

Lethal lithium poisoning with sustained-release preparations. M. Hrdlicka and P. Sevcik (C) 586

Transsexualism

Four-year remission after comorbid OCD improved with selfexposure therapy. Isaac $M$. Marks \& David Mataix-Cols 389-390

Trauma

Anxiety and depression in asylumseekers. J. J. Rodenburg et al (C) 394

Psychological consequences of road traffic accidents in children and adolescents. D. Fearnley (C) 393. A. Di Gallo (Author's reply) (C) 393

Psychological debriefing for victims of acute burn trauma. Jonathan I. Bisson et al 78-81. G. Turnbull et al (C) 582. J. I. Bisson \& P. L. Jenkins (Authors' reply) (C) 583. R. P. Kraus (C) 583. David Reiss \& Morven Leese (C) 583-584

PTSD symptoms and the Clapham rail accident. Carolyn Selley et al 478-482

War pensions. M. Atkins \& S. Davies (C) 188-189
Tricyclics

Cost-effectiveness of antidepressant treatment. L. Head \& V. O'Keane (C) 88

Discontinuation rates of SSRIs and tricyclics. I. Anderson \& C. Mortimore (C) 87. S. Lynch \& S. Curran (C) 87. M. Hotopf et al (Authors' reply) (C) 87-88

Suicide and cost-effectiveness of antidepressants. S. Lynch (C) 189

\section{Unipolar disorder}

Test of Xq26.3-28 linkage in bipolar and unipolar families. C. Smyth et al 578-581

United Kingdom

Adverse social circumstances and depression in people of Pakistani origin. Nusrat Husain et al 434-438

Cost-effectiveness of clozapine. A clinic-based study. Katherine J. Aitchison and Robert W. Kerwin 125-130

see also Britain

United States

Subjective experience of schizophrenia and depression among Latinos and Euro-Americans. Janis Hunter Jenkins 20-25

Urban populations

Determinants of GP recognition of psychological problems in a multiethnic inner-city health district. S. M. Odell et al 537-541

Effects of level of socio-economic development on course of nonaffective psychosis. Vijoy K. Varma et al 256-259

Urban environment and mental health. Odd Steffen Dalgard \& Kristian Tambs 530-536

Verona Service Satisfaction Schedule

Ethnic differences in satisfaction with mental health services. Sue Parkman et al 260-264

Violence

Crime, violence, and schizophrenia. P. Noble (C) 189-190

History of violent behaviour and schizophrenia in different cultures. Jan Volavka et al 9-14

Number needed to detain. S. Fleminger (C) 287

Risk assessment and clinical risk management. C. Jones (C) 290

Use of seclusion, restraint, and emergency medication. H. Sequeira \& S. Halstead (C) 288-289 
Vision impairment

Age-related cognitive decline and vision impairment affecting detection of dementia syndrome. Friedel M. Reischies \& Bernhard Geiselmann 449-451

Wang Scale

Rapid intravenous detoxification in heroin addicts. Albert Seoane et al 340-345

War pensions

M. Atkins \& S. Davies (C) 188-189

Weather

Fatal self-harm in North Cheshire. Emad Salib \& Nicola Gray 473-477

Wechsler Memory Scale

Poor memory, negative symptoms and abnormal movements in nevertreated patients with schizophrenia. R. G. McCreadie et al 360-363

Withdrawal syndromes

Paroxetine withdrawal syndrome in a neonate. M. L. Dahl et al (C) 391-392

Women

Common mental disorders in primary care in Harare, Zimbabwe. V. Patel et al 60-64

Disorders of the mother-infant relationship. I. F. Brockington (C) 486

Family planning needs and STD risk behaviours of psychiatric outpatients. John H. Coverdale et al 69-72

Seasonal well-being in the elderly. John M. Eagles et al 53-55

Severe disorders of mother-to-infant bonding. R. Channi Kumar 175-181 see also Gender differences, Girls, Pregnancy and Puerperium

World Health Organization

Study on Determinants of Outcome of Severe Mental Disorders Social course of schizophrenia.

A. Cohen \& S. Lee (C) 287.

T. Craig et al (Authors' reply) (C) 288

Violent behaviour and schizophrenia. Jan Volavka et al 9-14

\section{X chromosome}

Test of Xq26.3-28 linkage in bipolar and unipolar families. C. Smyth et al 578-581

\footnotetext{
Zimbabwe

Common mental disorders in primary care in Harare. V. Patel et al 60-64
}

Ayankaran, J. R. see McCreadie, R. G. et al 360-363

Abou-Saleh, M. T. see Ghubash, R. 65-68

Acuda, W. see Patel, V. et al 60-64

Adams, Clive E. Establishing costeffectiveness of antipsychotic drugs (C) 486

Adityanjee, M. D. et al. Eosinophilia, agranulocytosis and clozapine (C) 485-486

Adshead, G. see Lucey, J. V. et al 346-350

Agarwal, M. R. Subjective quality of life in schizophrenia (C) 392

Ahlner, J. see Dahl, M. L. et al (C) 391-392

Aitchison, K. J. see Kerwin, R. W. (C) 584

Aitchison, Katherine J. \& Kerwin, Robert W. Cost-effectiveness of clozapine. A UK clinic-based study 125-130

Aizenberg, D. see Shiloh, R. et al 569-573

Albert, Maya see Becker, Thomas et al 15-19

Alberts, J. L. see Speller, J. C. et al 564-568

Alexander, Julie see Bisson, Jonathan I. et al 78-81

Allart, Esther see van der Sande, Rob et al 35-41

Allen, Keith see Boardman, Anthony P. et al 457-462

Allen, R. L. et al. Neuropsychological and imaging differences in dementia with Lewy bodies and Alzheimer's disease (C) 486-487

Almeida-Filho, Naomar et al. Brazilian multicentric study of psychiatric morbidity. Methodological features and prevalence estimates 524-529

Álvarez, Miguel see Seoane, Albert et al 340-345

Amos, T. see Appleby, L. et al (C) 391

Anderson, I. \& Mortimore, C. Discontinuation rates of SSRIs and tricyclic antidepressants (C) 87

Anderson, Ian et al. Invited commentaries on: Closing the gap between research and practice (Evidence-based psychiatry) 226-227

Andreoli, Sérgio Baxter see AlmeidaFilho, Naomar et al 524-529

Andrews, Gavin see Boot, Brendon et al 242-246

Andrews, Gavin see Lindsay, Merran et al 135-139

Appleby, L. et al. Confidential Inquiry into Suicide and Homicide by People with Mental Illness (C) 391

Atkins, M. and Davies, S. War pensions (C) $188-189$
Bailey, P. Clozapine treatment, eosinophilia and agranulocytosis (C) 90

Baker, Sherryl see Volavka, Jan et al 9-14

Bale, Elizabeth see Hawton, Keith et al

Banerjee, Sube see Robertson, Mary M. et al 283-286

Bannister, Carol see Bisson, Jonathan I. et al 78-81

Barnes, T. R. E. see Speller, J. C. et al 564-568

Barrowclough, Christine \& Parle, Michael. Appraisal, psychological adjustment and expressed emotion in relatives of patients suffering from schizophrenia 26-30

Barry, S. see Lane, A. et al 550-555

Bearn, Jenny see Keaney, Francis et al (C) $484-485$

Bebbington, P. see Garety, P. et al 420-426

Bebbington, Paul see Bindman, Jonathan et al 169-174 Bebbington, Paul see Kuipers, Elizabeth et al 319-327

Becker, Thomas et al. Social networks and service use among representative cases of psychosis in South London 15-19

Bernadt, M. \& Stein, G. Lithium: evidence reconsidered (C) 484

Bhugra, D. see Hutchinson, G. et al 145-147

Bindman, Jonathan et al. Integration between primary and secondary services in the care of the severely mentally ill: patients' and general practitioners' views 169-174

Bird, Kevin D. see Vollmer-Conna, Ute et al 377-381

Bisson, J. I. \& Jenkins, P. L. Psychological debriefing for victims of acute burn trauma (Authors' reply) (C) 583

Bisson, Jonathan I. et al. Randomised controlled trial of psychological debriefing for victims of acute burn trauma 78-81

Biver, F. et al. Serotonin 5-HT receptor imaging in major depression: focal changes in orbitoinsular cortex 444-448

Blackburn, I.-M. \& Moore, R. G. Controlled acute and follow-up trial of cognitive therapy and pharmacotherapy in out-patients with recurrent depression 328-334

Bloch, Sidney see Szmukler, George I. (Editorial) 401-405

Blyler, Crystal R. see Fenton, Wayne S. et al 265-268 556-560 
Boardman, Anthony P. et al. Social indicators and the prediction of psychiatric admission in different diagnostic groups 457-462

Bolden, R. I. see Wall, T. D. et al 519-523

Bond, Alison see Hawton, Keith et al 556-560

Boneham, M. A. see McCracken, C. F. M. et al 269-273

Boot, Brendon et al. Disability, outcome and case-mix in acute psychiatric in-patient units 242-246

Borrill, C. S. see Wall, T. D. et al 519-523

Bouman, W. P. see Pinner, G. (C) 289

Bramble, D. see Taylor, N. (C) 393

Breslau, Naomi see Peterson, Edward L. (C) 487-488

Brewin, J. et al. Incidence of schizophrenia in Nottingham. A comparison of two cohorts, 1978 to 1980 and 1992 to $1994.140-144$

Brockington, I. F. Disorders of the mother-infant relationship (C) 486

Brown, Alan S. see Varma, Vijoy K. et al 256-259

Brown, Steve. Excess mortality of schizophrenia. A meta-analysis (Review Article) 502-508

Bruce, Irene see Kirby, Michael et al 369-372

Brynjolfsson, J. see Smyth, C. et al 578-581

Buckley, A. see Lee, A. S. et al (Authors' reply) (C) 187-188

Busatto, G. see Lucey, J. V. et al 346-350

Busatto, G. F. see Travis, M. J. et al (C) 290-291

Buskens, Erik see van der Sande, Rob et al 35-41

Busnello, Ellis D'Arrigo see AlmeidaFilho, Naomar et al 524-529

Busuttil, W. see Turnbull, G. et al (C) 582

Büyükberker, C. see Karaman, T. et al 31-34

Byram, Victoria see North, Clive et al 545-549

Cabré, Lluís see Seoane, Albert et al 340-345

Caligiuri, Michael P. et al. Incidence and risk factors for severe tardive dyskinesia in older patients 148-153

Cantwell, R. see Brewin, J. et al 140-144

Carrasco, Genís see Seoane, Albert et al 340-345

Carter, A. J. see Wall, T. D. et al 519-523

Caulet, Malijaï see Ohayon, Maurice M. et al 382-388

Chemerinski, Erán see Starkstein, Sergio E. et al 47-52
Chong, S.-A. Tardive dyskinesia and CYP2D6 polymorphism in Chinese (C) 586

Chong, S. A. \& Chua, L. Clozapine, Chinese and blood (C) 89-90

Christensen, Helen see Jorm, Anthony F. et al 233-237

Chua, L. see Chong, S. A. (C) 89-90

Cleave, N. see McCracken, C. F. M. et al 269-273

Coakley, Davis see Kirby, Michael et al 369-372

Coakley, Grainne see Scully, Paul J. et al 154-158

Cohen, A. and Lee, S. Social course of schizophrenia (C) 287

Cohen, Andrea and Eastman, Nigel. Needs assessment for mentally disordered offenders and others requiring similar services. Theoretical issues and a methodological framework (Review Article) 412-416

Coleman, Ken see Koffman, Jonathan et al 238-241

Commander, M. J. see Odell, S. M. et al 537-541

Cookson, John. Lithium: balancing risks and benefits (Evidence-based psychiatry) 120-124

Cooper, Peter J. \& Goodyer, Ian. Prevalence and significance of weight and shape concerns in girls aged 11 to 16 years $542-544$

Cooper, S. J. see Kelly, C. B. 182-186

Cooper, Z. see Hayhurst, H. et al 439-443

Copeland, J. R. M. see McCracken, C. F. M. et al 269-273

Coppola, R. see Knable, M. B. et al 574-577

Costa, D. C. see Lucey, J. V. et al 346-350

Costa, D. C. see Travis, M. J. et al (C) 290-291

Costa, Josep see Seoane, Albert et al 340-345

Coutinho, Evandro see Almeida-Filho, Naomar et al 524-529

Coverdale, John H. et al. Family planning needs and STD risk behaviours of female psychiatric outpatients 69-72

Cowen, P. J. see Fineberg, N. A. et al 280-282

Craig, T. et al. Social course of schizophrenia (Authors' reply) (C) 288

Creed, Francis see Husain, Nusrat et al 434-438

Creed, Francis see Ronalds, Clare et al 427-433

Crimlisk, Helen see Keaney, Francis et al (C) 484-485

Crino, Rocco see Lindsay, Merran et al 135-139
Crow, T. J. Influenza and schizophrenia (C) 91

Curran, S. see Lynch, S. (C) 87

Curson, D. A. see Speller, J. C. et al 564-568

Curtis, D. see Smyth, C. et al 578-581

Czobor, Pal see Volavka, Jan et al 9-14

Daborn, P. Psychiatry and the Church (C) 391

Dahl, M. L. et al. Paroxetine withdrawal syndrome in a neonate (C) 391-392

Dalgard, Odd Steffen \& Tambs, Kristian. Urban environment and mental health. A longitudinal study 530-536

Dalkin, T. see Brewin, J. et al 140-144

Damhaut, P. see Biver, F. et al 444-448

Davies, S. see Atkins, M. (C) 188-189

Davies, S. see Lee, A. S. et al (Authors' reply) (C) 187-188

Davies, Sara see Parkman, Sue et al 260-264

Dawe, Sharon see Strang, John et al 335-339

Deahl, M. see Lucey, J. V. et al 346-350

Deahl, Martin \& Turner, Trevor. General psychiatry in no-man's land (Editorial) 6-8

Deb, Shoumitro. Structural neuroimaging in learning disability (Review Article) 417-419

de Girolamo, Giovanni see Morlino, Massimo et al 452-456

DeLisi, L. E. Gender and age at onset of schizophrenia (C) 188

Derksen, P. see Heeren, T. J. et al (Authors' reply) (C) 289-290

Dernovsek, Z. \& Tavcar, R. Risperidone-induced leucopenia and neutropenia (C) 393-394

Di Gallo, A. Psychological consequences of road traffic accidents in children and adolescents (Author's reply) (C) 393

Dolan, Bridget et al. Change in borderline symptoms one year after therapeutic community treatment for severe personality disorder 274-279

Dorfman-Etrog, P. see Shiloh, R. et al 569-573

Douglas, A. Stuart see Eagles, John M. et al 53-55

Dunn, G. see Garety, P. et al 420-426

Dunn, Graham see Kuipers, Elizabeth et al 319-327

Eagles, John M. et al. Seasonal changes in psychological well-being in an elderly population $53-55$ 
Eastman, Nigel see Cohen, Andrea (Review Article) 412-416

Egan, M. F. see Knable, M. B. et al 574-577

Eisenberg, Leon. A very British kind of social psychiatry (Review Article, Michael Shepherd Memorial Symposium) 309-313

Ell, P. J. see Lucey, J. V. et al 346-350

Ell, P. J. see Travis, M. J. et al (C) 290-291

Fagg, Joan see Hawton, Keith et al 556-560

Fahy, T. A. see Hutchinson, G. et al 145-147

Fahy, Tom see Howard, Louise (Editorial) 497-500

Faria, F. Souza. General psychiatry in no-man's land (C) 483

Farrell, Michael see Hall, Wayne (Editorial) 4-5

Farrell, Michael see Neeleman, Jan (Editorial) 303-304

Fearnley, D. Psychological consequences of road traffic accidents in children and adolescents (C) 393

Fenton, Wayne S. et al. Prevalence of spontaneous dyskinesia in schizophrenic and non-schizophrenic psychiatric patients 265-268

Fernandes, Jefferson see Almeida-Filho, Naomar et al 524-529

Fineberg, N. A. et al. Brain 5-HT function in obsessive-compulsive disorder. Prolactin responses to d-fenfluramine 280-282

Fleminger, S. Number needed to detain (C) 287

Forbes, John F. see Lang, Fiona H. et al 159-164

Fowler, D. see Garety, P. et al 420-426

Fowler, David see Kuipers, Elizabeth et al 319-327

Fox, R. see Brewin, J. et al 140-144

Fox Hiley, Paul J. see Robertson, Mary M. et al 283-286

França, Josimar Farias see AlmeidaFilho, Naomar et al 524-529

Franken, I. H. A. and Hendriks, V. M. Comorbidity of mental disorders with substance misuse (C) 485

Franz, M. Subjective quality of life in schizophrenia (Author's reply) (C) 392

Freeman, D. see Garety, P. et al 420-426

Freeman, Daniel see Kuipers, Elizabeth et al 319-327

Fulop, Naomi J. see Koffman, Jonathan et al 238-241

Gacinovic, S. see Lucey, J. V. et al 346-350
Gacinovic, S. see Travis, M. J. et al (C) 290-291

Garety, P. et al. London-East Anglia randomised controlled trial of cognitive-behavioural therapy for psychosis. II: Predictors of outcome 420-426

Garety, Philippa see Kuipers, Elizabeth et al 319-327

Gask, Linda. Listening to patients (Editorial) 301-302

Gavrilovic, M. see Pelc, I. et al 73-77

Geddes, J. R. see Powell, J. A. (C) 586-587

Geddes, John R. \& Harrison, Paul J. Closing the gap between research and practice (Evidence-based psychiatry) 220-225

Geerlings, Mirjam I. see Schmand, Ben et al 373-376

Geiselmann, Bernhard see Reischies, Friedel M. 449-451

Ghubash, R. and Abou-Saleh, M. T. Postpartum psychiatric illness in Arab culture: prevalence and psychosocial correlates 65-68

Gilbody, Simon M. see Anderson, Ian et al (Evidence-based psychiatry) 226-227

Gilvarry, C. see Hutchinson, G. et al $145-147$

Gilvarry, K. see Van Os, J. et al (Authors' reply) (C) 289

Glazebrook, C. see Brewin, J. et al 140-144

Gledhill, Julia A. et al. Psychiatrists and their patients: views on forms of dress and address 228-232

Glover, Vivette. Maternal stress or anxiety in pregnancy and emotional development of the child (Editorial) 105-106

Gogliettino, Angela see Morlino, Massimo et al 452-456

Goldman, S. see Biver, F. et al 444-448

Golya, D. A. see Wall, T. D. et al 519-523

Goodyer, Ian see Cooper, Peter J. 542-544

Gorey, J. see Knable, M. B. et al 574-577

Gossop, Michael see Strang, John et al 335-339

Gowers, Simon see North, Clive et al 545-549

Gray, Jeffrey see Strang, John et al 335-339

Gray, Nicola see Salib, Emad 473-477

Grunberg, Frédéric see Proulx, France et al 247-250

Guilleminault, Christian see Ohayon, Maurice M. et al 382-388

Gurling, H. see Smyth, C. et al 578-581

Gwanzura, F. see Patel, V. et al 60-64
Hadley, C. see Garety, P. et al 420-426

Hadley, Clare see Kuipers, Elizabeth et al 319-327

Hall, W. Cannabis and schizophrenia (Author's reply) (C) 584-585

Hall, Wayne see Boot, Brendon et al 242-246

Hall, Wayne and Farrell, Michael. Comorbidity of mental disorders with substance misuse (Editorial) 4-5

Hall, Wayne \& Solowij, Nadia. Longterm cannabis use and mental health (Editorial) 107-108

Halstead, S. see Sequeira, H. (C) 288-289

Hansen, V. Long-term mortality after first psychiatric admission (C) 187

Hardy, G. E. see Wall, T. D. et al 519-523

Hardy, R. see Hotopf, M. et al (Authors' reply) (C) 87-88

Harrison, G. see Brewin, J. et al 140-144

Harrison, Paul J. see Geddes, John R. (Evidence-based psychiatry) 220-225

Harrison-Read, P. Prejudice against providers of psychiatric services for Black people (C) 582

Haruna, Adam Y. see Suleiman, Toyin G. et al 364-368

Hawton, Keith see Lewis, Glyn et al 351-354

Hawton, Keith see van der Sande, Rob et al 35-41

Hawton, Keith et al. Trends in deliberate self-harm in Oxford, 1985 to 1995. Implications for clinical services and the prevention of suicide 556-560

Hayhurst, H. et al. Expressed emotion and depression. A longitudinal study 439-443

Haynes, C. E. see Wall, T. D. et al 519-523

Head, L. and O'Keane, V. Costeffectiveness of antidepressant treatment (C) 88

Heeren, T. J. et al. Treatment, outcome and predictors of response in elderly depressed in-patients (Authors' reply) (C) $289-290$

Heinz, A. see Knable, M. B. et al 574-577

Henderson, Scott see Jorm, Anthony F. et al 233-237

Hendriks, V. M. see Franken, I. H. A. (C) 485

Hepple, Jason and Quinton, Catherine. One hundred cases of attempted suicide in the elderly 42-46

Hernández, Eustaqui see Seoane, Albert et al 340-345

Herrod, J. J. see Michael, A. (C) 90

Heycop Ten Ham, B. F. v. see Heeren, T. J. et al (Authors' reply) (C) 289-290 
Hickie, Ian see Vollmer-Conna, Ute et al 377-381

Hodgson, Richard E. see Boardman, Anthony P. et al 457-462

Hopper, K. see Craig, T. et al (Authors' reply) (C) 288

Hotopf, M. et al. Discontinuation rates of SSRIs and tricyclic antidepressants (Authors' reply) (C) 87-88

Hovens, J. E. see Rodenburg, J. J. et al (C) 394

Howard, Louise and Fahy, Tom. Liver transplantation for alcoholic liver disease (Editorial) 497-500

Howard, Robert and Rabins, Peter. Late paraphrenia revisited (Editorial) 406-408

Hrdlicka, M. and Sevcik, P. Lethal lithium poisoning with sustainedrelease preparations (C) 586

Husain, Nusrat et al. Adverse social circumstances and depression in people of Pakistani origin in the UK 434-438

Hutchinson, G. et al. Increased rate of psychosis among African-Caribbeans in Britain is not due to an excess of pregnancy and birth complications 145-147

Jacomb, Patricia A. see Jorm, Anthony F. et al 233-237

Jampala, V. Chowdary see Adityanjee, M. D. et al (C) $485-486$

Jelicic, M. and Kempen, G. I. J. M. Cognitive function and fall-related fractures (C) 88-89

Jenkins, Janis Hunter. Subjective experience of persistent schizophrenia and depression among US Latinos and Euro-Americans 20-25

Jenkins, P. L. see Bisson, J. I. (Authors' reply) (C) 583

Jenkins, Peter L. see Bisson, Jonathan I. et al 78-81

Jeste, Dilip V. see Caligiuri, Michael P. et al 148-153

Johnson, Sonia see Becker, Thomas et al 15-19

Johnson, Sonia see Bindman, Jonathan et al 169-174

Johnson, Sonia. Dual diagnosis of severe mental illness and substance misuse: a case for specialist services? (Editorial) 205-208

Johnstone, Eve C. see Lang, Fiona H. et al 159-164,165-168

Jones, C. Risk assessment and clinical risk management (C) 290

Jones, P. see Van Os, J. et al (Authors' reply) (C) 289

Jones, Peter see Lewis, Glyn et al 351-354
Jones, Roger see Scott, Christine et al 131-134

Jones, S. see Garety, P. et al 420-426

Jonker, Cees see Schmand, Ben et al 373-376

Jorm, Anthony F. et al. Helpfulness of interventions for mental disorders: beliefs of health professionals compared with the general public 233-237

Kalsi, G. see Smyth, C. et al 578-581

Kar, N. see Sengupta, S. (C) 587

Karaman, T. et al. Bereitschaftpotential in schizophrenia 31-34

Katona, C. L. E. see Allen, R. L. et al 486-487

Katona, Cornelius see Livingston, Gill et al 56-59

Keaney, Francis et al. Comorbidity of mental disorders with substance misuse (C) 484-485

Kelly, C. B. and Cooper, S. J. Plasma noradrenaline response to electroconvulsive therapy in depressive illness 182-186

Kempen, G. I. J. M. see Jelicic, M. (C) 88-89

Kennedy, Peter see Robert, Glenn (Editorial) 103-104

Kerwin, R. W. see Lucey, J. V. et al 346-350

Kerwin, R. W. see Travis, M. J. et al (C) 290-291

Kerwin, R. W. and Aitchison, K. J. Cost-effectiveness of clozapine (C) 584

Kerwin, Robert W. see Aitchison, Katherine J. 125-130

Kessler, Ronald C. Large same-year effects: fact or artefact? (Author's reply) (C) 488

Keville, R. see Lane, A. et al 550-555

Khaikin, M. see Shiloh, R. et al 569-573

Khare, C. B. see Varma, Vijoy K. et al 256-259

King, Elizabeth see Selley, Carolyn et al 478-482

King, Michael see Gledhill, Julia A. et al 228-232

Kinsella, A. see Lane, A. et al 550-555

Kinsella, Anthony see Scully, Paul J. et al 154-158

Kirby, Michael et al. Mental disorders among the community-dwelling elderly in Dublin 369-372

Kleijn, W. C. see Rodenburg, J. J. et al (C) 394

Knable, M. B. et al. Altered dopaminergic function and negative symptoms in drug-free patients with schizophrenia. $\left[{ }^{123} \mathrm{I}\right]$-iodobenzamide SPECT study 574-577
Knapp, Martin. Costs of schizophrenia (Review Article) 509-518

Koffman, Jonathan et al. Ethnicity and use of acute psychiatric beds: oneday survey in North and South Thames regions 238-241

Korten, Ailsa E. see Jorm, Anthony F. et al 233-237

Kraus, R. P. Psychological debriefing for victims of acute burn trauma (C) 583

Krivelevich, Ilya see Volavka, Jan et al 9-14

Kuipers, E. see Garety, P. et al 420-426

Kuipers, Elizabeth see Bindman, Jonathan et al 169-174

Kuipers, Elizabeth et al. London-East Anglia randomised controlled trial of cognitive-behavioural therapy for psychosis. I: Effects of the treatment phase 319-327

Kumar, R. Channi. "Anybody's child": severe disorders of mother-to-infant bonding 175-181

Kuzis, Gabriela see Starkstein, Sergio E. et al 47-52

Kwiecinski, R. see Brewin, J. et al 140-144

Lacro, Jonathan P. see Caligiuri, Michael P. et al 148-153

Lane, A. et al. Postnatal depression and elation among mothers and their partners: prevalence and predictors 550-555

Lang, F. H. Role of GPs in service provision for people with schizophrenia (Author's reply) (C) 585-586

Lang, Fiona H. et al. Service provision for people with schizophrenia

I. Clinical and economic perspective 159-164

II. Role of the general practitioner 165-168

Laska, Eugene see Volavka, Jan et al 9-14

Latha, S. see McCreadie, R. G. et al 360-363

Laugharne, R. Clinical trials: severe mental illness and substance misuse (C) 587

Lawal, Rahman A. see Suleiman, Toyin G. et al 364-368

Lawlor, Brian A. see Kirby, Michael et al 369-372

Le Bon, O. see Pelc, I. et al 73-77

Lee, A. S. et al. Long-term mortality after first psychiatric admission (Authors' reply) (C) 187-188

Lee, K. S. see Knable, M. B. et al 574-577

Lee, S. see Cohen, A. (C) 287

Leese, Morven see Becker, Thomas et al 15-19 
Leese, Morven see Parkman, Sue et al 260-264

Leese, Morven see Reiss, David (C) 583-584

Leff, J. see Hutchinson, G. et al 145-147

Lehert, P. see Pelc, I. et al 73-77

Leiguarda, Ramón see Starkstein, Sergio E. et al 47-52

Lemon, Jim see Vollmer-Conna, Ute et al 377-381

Lesage, Alain D. see Proulx, France et al 247-250

Lewis, G. see Hotopf, M. et al (Authors' reply) (C) 87-88

Lewis, Glyn see Anderson, Ian et al (Evidence-based psychiatry) 226-227

Lewis, Glyn et al. Strategies for preventing suicide 351-354

Lewis, Martyn see Boardman, Anthony P. et al 457-462

Lin, S. see Craig, T. et al (Authors' reply) (C) 288

Lindeboom, Jaap see Schmand, Ben et al 373-376

Lindsay, Merran et al. Controlled trial of exposure and response prevention in obsessive-compulsive disorder 135-139

Lion, K. see Pelc, I. et al 73-77

Lisanti, Felice see Morlino, Massimo et al 452-456

Livingston, Gill et al. Costs of community care for older people 56-59

Lloyd, Andrew see Vollmer-Conna, Ute et al 377-381

Longhurst, J. G. BSE and human prion disease (C) 290

Longhurst, J. G. Cannabis and schizophrenia (C) 584

Lonnqvist, Jouko see Ohberg, Annakatri et al 468-472

Lotstra, F. see Biver, F. et al 444-448

Lucey, J. V. et al. Brain blood flow in anxiety disorders. OCD, panic disorder with agoraphobia, and posttraumatic stress disorder on $99 \mathrm{~m}$ TcHMPAO single photon emission tomography (SPET) 346-350

Lynch, S. Suicide and the costeffectiveness of antidepressants (C) 189

Lynch, S. and Curran, S. Discontinuation rates of SSRIs and tricyclic antidepressants (C) 87

McAdams, Lou Ann see Caligiuri, Michael P. et al 148-153

McCracken, C. F. M. et al. Prevalence of dementia and depression among people in Black and ethnic minorities 269-273

McCreadie, R. G. et al. Poor memory, negative symptoms and abnormal movements in never-treated Indian patients with schizophrenia 360-363
McCrone, Paul see Becker, Thomas et al 15-19

McCrone, Paul and Thornicroft, Graham. Health economics (Reading about) 191-193

McGlashan, Thomas H. see Fenton, Wayne S. et al 265-268

McGuffin, Peter see Owen, Michael J. (Editorial) 201-202

McKibbin, P. see McCracken, C. F. M. et al 269-273

McLeod, Isabella H. see Eagles, John M. et al 53-55

MacLeod, M. see Stark, C. et al (C) 187

Mak, Vivienne see Neeleman, Jan et al 463-467

Mallett, R. see Hutchinson, G. et al 145-147

Manela, Monica see Livingston, Gill et al 56-59

Mann, A. see Patel, V. et al 60-64

Mann, Anthony. The evolving face of psychiatric epidemiology (Review Article, Michael Shepherd Memorial Symposium) 314-318

Marcelis, M. see Van Os, J. et al (Authors' reply) (C) 289

Mari, Jair de Jesus see Almeida-Filho, Naomar et al 524-529

Marks, I. M. see Lucey, J. V. et al 346-350

Marks, Isaac see Strang, John et al 335-339

Marks, Isaac M. \& Mataix-Cols, David. Four-year remission of transsexualism after comorbid obsessive-compulsive disorder improved with self-exposure therapy. Case report 389-390

Martin, Nick see Selley, Carolyn et al 478-482

Mataix-Cols, David see Marks, Isaac M. 389-390

Mayer, Birgit see Muris, Peter et al 82-86

Mayou, Richard A. Psychiatry, medicine and consultation-liaison (Editorial) 203-204

Medley, I. see Brewin, J. et al 140-144

Meisner, Morris see Volavka, Jan et al 9-14

Mendlewicz, J. see Biver, F. et al 444-448

Menon, D. K. see Varma, Vijoy K. et al 256-259

Merckelbach, Harald see Muris, Peter et al 82-86

Merskey, $\mathrm{H}$. Tests of 'dissociation' and mood disorder (C) 487

Mertens, J. see Travis, M. J. et al (C) 290-291

Michael, A. and Herrod, J. J. Citalopram-induced decreased libido (C) 90
Middelboe, Thomas. Prospective study of clinical and social outcome of stay in small group homes for people with mental illness 251-255

Miller, Bruce L. Clinical advances in degenerative dementias (Editorial) 1-3

Misra, Arun K. see Varma, Vijoy K. et al 256-259

Modai, I. see Shiloh, R. et al 569-573

Mohan, Madan S. see Adityanjee, M. D. et al (C) 485-486

Molina, Ricard see Seoane, Albert et al 340-345

Moloney, E. see Smyth, C. et al 578-581

Moncrieff, Joanna. Lithium: evidence reconsidered (Evidence-based psychiatry) 113-119

Montgomery, S. A. see Fineberg, N. A. et al 280-282

Moore, R. G. see Blackburn, I.-M. 328-334

Moran, P. see Hutchinson, G. et al 145-147

Morgan, H. G. and Stanton, Ruth. Suicide among psychiatric in-patients in a changing clinical scene. Suicidal ideation as a paramount index of short-term risk 561-563

Morlino, Massimo et al. Publication trends of papers on schizophrenia. A 15 -year analysis of three general psychiatric journals 452-456

Morris, M. see Lane, A. et al 550-555

Mortensen, P. B. see Rossau, C. D. 355-359

Mortimore, C. see Anderson, I. (C) 87

Mulligan, R. see Travis, M. J. et al (C) 290-291

Muris, Peter et al. Eye movement desensitisation and reprocessing versus exposure in vivo. A singlesession crossover study of spiderphobic children 82-86

Murphy, P. see Smyth, C. et al 578-581

Murray, Gordon D. see Lang, Fiona H. et al 159-164,165-168

Murray, R. see Van Os, J. et al (Authors' reply) (C) 289

Murray, R. M. see Hutchinson, G. et al 145-147

Naik, P. C. see Lee, A. S. et al (Authors' reply) (C) 187-188

Neeleman, Jan et al. Suicide by age, ethnic group, coroners' verdicts and country of birth. A three-year survey in inner London 463-467

Neeleman, Jan and Farrell, Michael. Suicide and substance misuse (Editorial) 303-304

Noble, P. Crime, violence, and schizophrenia (C) 189-190 
North, Clive et al. Family functioning and life events in the outcome of adolescent anorexia nervosa 545-549

Norton, Kingsley see Dolan, Bridget et al 274-279

Obholzer, Anton. Reports on psychotherapy commissioned by the National Health Service Executive (Editorial) 495-496

O'Brien, F. see Stark, C. et al (C) 187

Odell, S. M. et al. Determinants of general practitioner recognition of psychological problems in a multi-ethnic inner-city health district 537-541

Ohaeri, Jude U. see Suleiman, Toyin G. et al 364-368

Ohayon, Maurice M. et al. DSM-IV and ICSD-90 insomnia symptoms and sleep dissatisfaction 382-388

Ohberg, Annakatri et al. Driver suicides $468-472$

O'Keane, V. see Head, L. (C) 88

Olhager, E. see Dahl, M. L. et al (C) 391-392

O'Neill, J. see Smyth, C. et al 578-581

Orija, O. B. see Suleiman, Toyin G. et al 364-368

Osola, Karen see Selley, Carolyn et al 478-482

Owen, Michael J. \& McGuffin, Peter. Genetics and psychiatry (Editorial) 201-202

Özkaynak, S. see Karaman, T. et al 31-34

Padmavathi, R. see McCreadie, R. G. et al 360-363

Pantelis, C. see Speller, J. C. et al 564-568

Parkman, Sue et al. Ethnic differences in satisfaction with mental health services among people with psychosis in South London: PRiSM Study 4. 260-264

Parle, Michael see Barrowclough, Christine 26-30

Pashley, David see Koffman, Jonathan et al 238-241

Patel, V. et al. Common mental disorders in primary care in Harare, Zimbabwe: associations and risk factors $60-64$

Paykel, E. S. see Hayhurst, H. et al 439-443

Pelc, I. et al. Efficacy and safety of acamprosate in the treatment of detoxified alcohol-dependent patients. A 90-day placebo-controlled dose-finding study 73-77

Penttila, Antti see Ohberg, Annakatri et al 468-472

Peterson, Edward L. and Breslau, Naomi. Large same-year effects: fact or artefact? (C) $487-488$
Petracca, Gustavo see Starkstein, Sergio E. et al 47-52

Petursson, H. see Smyth, C. et al 578-581

Peveler, Robert see Selley, Carolyn et al 478-482

Phelan, Michael see Parkman, Sue et al 260-264

Phookun, Hemen R. see Varma, Vijoy K. et al 256-259

Pierides, M. Clozapine monotherapy and ketoacidosis (C) 90-91

Pilowsky, L. see Lucey, J. V. et al 346-350

Pilowsky, L. S. see Travis, M. J. et al (C) 290-291

Pinner, G. and Bouman, W. P. Treatment, outcome and predictors of response in elderly depressed inpatients (C) 289

Pittman, S. see Turnbull, G. et al (C) 582

Plomin, Robert see Rutter, Michael (Review Article) 209-219

Polge, C. Sigmund: a European database of mental health surveys (C) 91

Pollitt, Penelope see Jorm, Anthony F. et al 233-237

Powell, J. A. \& Geddes, J. R.Evidencebased psychiatry (C) 586-587

Powell, Jane see Strang, John et al 335-339

Priest, Robert G. see Ohayon, Maurice M. et al 382-388

Proulx, France et al. One hundred inpatient suicides 247-250

Puiggrós, Ana see Seoane, Albert et al 340-345

Quinton, Catherine see Hepple, Jason $42-46$

Rabins, Peter see Howard, Robert (Editorial) 406-408

Radic, Alicja see Kirby, Michael et al 369-372

Radwan, M. see Shiloh, R. et al 569-573

Ramana, R. see Hayhurst, H. et al 439-443

Reischies, Friedel M. and Geiselmann, Bernhard. Age-related cognitive decline and vision impairment affecting the detection of dementia syndrome in old age 449-451

Reiss, David and Leese, Morven. Psychological debriefing for victims of acute burn trauma (C) 583-584

Richards, David see Strang, John et al 335-339

Rick, J. E. see Wall, T. D. et al 519-523

Rifkin, L. see Smyth, C. et al 578-581

Ritchie, Karen. Eugeria, longevity and normal ageing (Editorial) 501
Robert, Glenn and Kennedy, Peter. Establishing cost-effectiveness of atypical neuroleptics (Editorial) 103-104

Roberts, A. see Fineberg, N. A. et al 280-282

Roberts, D. Transcending barriers between religion and psychiatry (C) 188

Roberts, Helen see Coverdale, John $\mathbf{H}$. et al 69-72

Robertson, Mary M. et al. Personality disorder and psychopathology in Tourette's syndrome: a controlled study 283-286

Rockwell, Enid see Caligiuri, Michael P. et al 148-153

Rodenburg, J. J. et al. Anxiety and depression in asylum-seekers (C) 394

Rodgers, Bryan see Jorm, Anthony F. et al 233-237

Rollin, Henry. Lunacy in London. Lunacy in Edinburgh (One hundred years ago) 91

Rollin, Henry. Mental disease outpatients (One hundred years ago) 587-588

Rollin, Henry. Royal Lunatic Asylum, Montrose (One hundred years ago) 190

Rollin, Henry. The Lunacy Act, 1890, and its amendments (One hundred years ago) 290-291

Rollin, Henry. The Lunacy Act, 1890, and its amendments (One hundred years ago) 488-489

Rollin, Henry. The Moscow meeting (One hundred years ago) 394

Ronalds, Clare et al. Outcome of anxiety and depressive disorders in primary care $427-433$

Rossau, C. D. and Mortensen, P. B. Risk factors for suicide in patients with schizophrenia: nested casecontrol study 355-359

Rous, David E. Grey matter correlates of syndromes in schizophrenia (C) 484

Rutter, Michael and Plomin, Robert. Opportunities for psychiatry from genetic findings (Review Article) 209-219

Ryan, A. Psychopathological syndromes and familial morbid risk of psychosis (C) 289

Sabe, Liliana see Starkstein, Sergio E. et al 47-52

Salib, Emad and Gray, Nicola. Weather conditions and fatal self-harm in North Cheshire 1989 to $1993.473-477$

Sartorius, N. see Craig, T. et al (Authors' reply) (C) 288

Sashidharan, S. P. see Odell, S. M. et al 537-541

Schmand, Ben et al. Subjective memory complaints in the elderly: depressive symptoms and future dementia 373-376 
Schwartz, B. see Shiloh, R. et al 569-573

Scott, A. see McCracken, C. F. M. et al 269-273

Scott, Christine et al. Acute and oneyear outcome of a randomised controlled trial of brief cognitive therapy for major depressive disorder in primary care 131-134

Scott, Jan see Scott, Christine et al 131-134

Scully, Paul J. et al. Executive (frontal) dysfunction and negative symptoms in schizophrenia: apparent gender differences in 'static' v. 'progressive' profiles 154-158

Selley, Carolyn et al. Post-traumatic stress disorder symptoms and the Clapham rail accident $478-482$

Sengupta, S. \& Kar, N. Subjective quality of life and drug treatment for schizophrenia (C) 587

Seoane, Albert et al. Efficacy and safety of two new methods of rapid intravenous detoxification in heroin addicts previously treated without success 340-345

Sequeira, H. and Halstead, S. Use of seclusion, restraint, and emergency medication (C) 288-289

Sevcik, P. see Hrdlicka, M. (C) 586

Sham, P. see Van Os, J. et al (Authors' reply) (C) 289

Shapiro, D. A. see Wall, T. D. et al 519-523

Shaw, J. see Appleby, L. et al (C) 391

Sheldon, Trevor A. see Anderson, Ian et al (Evidence-based psychiatry) 226-227

Shiloh, R. et al. Sulpiride augmentation in people with schizophrenia partially responsive to clozapine. A double-blind, placebo-controlled study 569-573

Siegel, C. see Craig, T. et al (Authors' reply) (C) 288

Sikdar, Sudip. Evidence-based psychiatry: which evidence to believe? (C) 483-484

Simkin, Sue see Hawton, Keith et al 556-560

Simpson, R. J. Role of GPs in service provision for people with schizophrenia (C) 585

Simunyu, E. see Patel, V. et al 60-64

Singh, Swaran P. Ethnicity in psychiatric epidemiology: need for precision (Editorial) 305-308

Smyth, C. et al. Test of Xq26.3-28 linkage in bipolar and unipolar affective disorder in families selected for absence of male to male transmission 578-581

Sobrepere, Gaudi see Seoane, Albert et al 340-345
Solowij, Nadia see Hall, Wayne (Editorial) 107-108

Speller, J. C. et al. One-year, low-dose neuroleptic study of in-patients with chronic schizophrenia characterised by persistent negative symptoms. Amisulpride v. haloperidol 564-568

Stanton, Ruth see Morgan, H. G. 561-563

Stark, C. et al. Long-term mortality after first psychiatric admission (C) 187

Starkstein, Sergio E. et al. Prospective longitudinal study of depression and anosognosia in Alzheimer's disease 47-52

Stein, G. see Bernadt, M. (C) 484

Stone, Kit see Ronalds, Clare et al 427-433

Strang, John et al. Type of hospital setting and treatment outcome with heroin addicts. Results from a randomised trial 335-339

Suleiman, Toyin G. et al. Financial cost of treating out-patients with schizophrenia in Nigeria 364-368

Surtees, P. G. see Odell, S. M. et al 537-541

Susser, Ezra S. see Varma, Vijoy K. et al 256-259

Sykes, R. Chronic fatigue syndrome (C) 393

Szabadi, E. Clozapine-induced hypersalivation (C) 89

Szmukler, George see Bindman, Jonathan et al 169-174

Szmukler, George I. \& Bloch, Sidney. Family involvement in the care of people with psychoses. An ethical argument (Editorial) 401-405

Tacchi, Mary Jane see Scott, Christine et al 131-134

Takei, N. see Hutchinson, G. et al 145-147

Tambs, Kristian see Dalgard, Odd Steffen 530-536

Tannock, Charles see Robertson, Mary M. et al 283-286

Tavcar, R. see Dernovsek, Z. (C) 393-394

Taylor, David. Pharmacokinetic interactions involving clozapine (Review Article) 109-112

Taylor, David M. Establishing costeffectiveness of antipsychotic drugs (C) 486

Taylor, N. \& Bramble, D. Sleep disturbance and Huntington's disease (C) 393

Terriere, D. see Travis, M. J. et al (C) 290-291

Tesón, Alejandra see Starkstein, Sergio E. et al 47-52

Thara, R. see McCreadie, R. G. et al 360-363
Thompson, Chris see Selley, Carolyn et al 478-482

Thornicroft, Graham see Becker, Thomas et al 15-19 Thornicroft, Graham see Bindman, Jonathan et al 169-174 Thornicroft, Graham see McCrone, Paul (Reading about) 191-193

Thornicroft, Graham see Parkman, Sue et al 260-264

Todd, C. see Patel, V. et al 60-64

Tomenson, Barbara see Husain, Nusrat et al 434-438

Tomenson, Barbara see Ronalds, Clare et al 427-433

Travis, M. see Lucey, J. V. et al 346-350

Travis, M. J. et al. Serotonin: 5-HT receptor occupancy in vivo and response to the new antipsychotics olanzapine and sertindole (C) 290-291

Treasure, J. Anorexia and the overvalued idea (C) 190

Tripathi, B. M. see Varma, Vijoy K. et al 256-259

Turbott, Sarah H. see Coverdale, John H. et al 69-72

Turnbull, G. et al. Psychological debriefing for victims of acute burn trauma (C) 582

Turner, David see Becker, Thomas et al 15-19

Turner, M. see Lane, A. et al 550-555

Turner, Mark. Malingering (Editorial) 409-411

Turner, Trevor see Deahl, Martin (Editorial) 6-8

van der Graaf, Yolanda see van der Sande, Rob et al 35-41

van der Sande, Rob et al. Intensive inpatient and community intervention versus routine care after attempted suicide. A randomised controlled intervention study $35-41$

van Engeland, Herman see van der Sande, Rob et al 35-41

Van Gent, P. P. J. see Heeren, T. J. et al (Authors' reply) (C) 289-290

van Haaften, Hans see Muris, Peter et al 82-86

Van Os, J. et al. Psychopathological syndromes and familial morbid risk of psychosis (Authors' reply) (C) 289

van Rooijen, Liesbeth see van der Sande, Rob et al 35-41

Varma, Vijoy K. et al. Effects of level of socio-economic development on course of non-affective psychosis 256-259

Vearnals, S. see Hayhurst, H. et al 439-443

Verbanck, P. see Pelc, I. et al 73-77 
Volavka, Jan et al. History of violent behaviour and schizophrenia in different cultures. Analyses based on the WHO study on Determinants of Outcome of Severe Mental Disorders 9-14

Vollmer-Conna, Ute et al. Cognitive deficits in patients suffering from chronic fatigue syndrome, acute infective illness or depression 377-381

Waddington, John L. see Scully, Paul J. et al 154-158

Wainwright, N. W. J. see Odell, S. M. et al 537-541

Wakefield, Denis see Vollmer-Conna, Ute et al 377-381

Walker, Z. see Allen, R. L. et al 486-487

Wall, T. D. et al. Minor psychiatric disorder in NHS trust staff: occupational and gender differences 519-523

Warner, James P. see Gledhill, Julia A. et al 228-232

Warren, Fiona see Dolan, Bridget et al 274-279

Webb, Sarah see Ronalds, Clare et al $427-433$

Weinberger, D. R. see Knable, M. B. et al 574-577

Weizman, A. see Shiloh, R. et al 569-573

Wessely, Simon see Neeleman, Jan et al 463-467

Wessely, Simon. Chronic fatigue syndrome (Reading about) 92-93

West, M. A. see Wall, T. D. et al 519-523

Westbrook, Reginald F. see VollmerConna, Ute et al 377-381

Wig, N. N. see Varma, Vijoy K. et al 256-259

Wikler, D. see Biver, F. et al 444-448

Williams, K. E. see McCracken, C. F. M. et al 269-273

Wilson, K. see McCracken, C. F. M. et al 269-273

Winston, M. see Patel, V. et al 60-64

Wright, Steve see Bindman, Jonathan et al 169-174

Wyatt, Richard J. see Fenton, Wayne S. et al 265-268

Yaltkaya, K. see Karaman, T. et al 31-34

Yorston, G. Depressive delusions and the general election (C) 585

Zemishlany, Z. see Shiloh, R. et al 569-573 schizophrenia: implications for presynaptic dopamine dysfunction (Louise Golightly) 591

Baltes, Margaret $\mathbf{M}$. The many faces of dependency in old age (Vincent Kirchner) 298

Beard, Jonathan C. Illicit drug use. Acute and chronic pharmacological intervention (Susan M. Ruben) 97

Blackburn, Ivy-Marie \& Twaddle, Vivien. Cognitive therapy in action: a practitioner's casebook (Gillian Butler) 295-296

Breggin, P. R. \& Stern, E. M. Psychosocial approaches to deeply disturbed persons (Frank Holloway) 493

Bright, Ruth. Grief and powerlessness: helping people regain control of their lives (Graeme Feggetter) 298

Bryan, K. and Maxim, J. (eds). Communication disability and the psychiatry of old age (Brian A. Lawlor) 94-95

Busfield, Joan. Men, women and madness: understanding gender and mental disorder (Rosalind Ramsay) 194

Clark, D. H. The story of a mental hospital: Fulbourn 1858 to 1983 (Douglas Bennett) 293-294

Cohen, Robert M. Patient management problems for the MRCPsych (Ashok G. Patel) 593

Committee on Cultural Psychiatry, Group for the Advancement of Psychiatry Report No. 141. Alcoholism in the United States: racial and ethnic considerations (Bruce Ritson) 595

Conacher, Geoffrey Neil. Management of the mentally disordered offender in prisons (Will Walker) 296

Cordess, C. \& Cox, M. C. (eds). Forensic psychotherapy. Crime, psychodynamics and the offender patient (Volumes 1 and 2) (Gisli $\mathrm{H}$. Gudjonsson) 100-101

Crawford, Isaiah, Crawford \& Fishman, Baruch (eds). Psychosocial interventions in HIV disease: a stagefocused and culture-specific approach (Paul Flowers) 299

Esiri, Margaret M. and Morris, James H. (eds). The neuropathology of dementia (John O’Brien) 590

Friedhoff, Arnold J. \& Amin, Farooq (eds). Plasma homovanillic acid in
Gelder, M., Gath, D., Mayou, R. \& Cowen, P. (eds). Oxford textbook of psychiatry (3rd edition) (Michael King) 96

Gersie, Alida (ed.). Dramatic approaches to brief therapy (Jim Wilson) 592

Gill, Eliana. Treating abused adolescents (Nick Goddard) 97

Goldsmith, Malcolm. Hearing the voice of people with dementia: opportunities and obstacles (David Jolley) 98-99

Goodman, Neville W. and Edwards, Martin B. Medical writing: a prescription for clarity (2nd edn) (Andrew Morris) 490-491

Green, John \& McCreaner, Alana. Counselling in HIV infection and AIDS (2nd edn) (Bernard Ratigan) 491

Grubin, Don. Fitness to plead in England and Wales (Maudsley 101

Grubrich-Simitis, I. Back to Freud's text: making silent documents speak (Jonathan Sklar) 592-593

Guthrie, Elspeth and Creed, Francis (eds). Seminars in liaison psychiatry (George Masterton) 96-97

Haber, Russell. Dimensions of psychotherapy supervision - maps and means (Julian M. Stern) 95-96

Harris, John, Allen, David, Cornick, Marion, Jefferson, Alan \& Mills, Richard. Physical interventions: a policy framework (T. P. Berney) 493

Haslam, M. T. Clifton Hospital - an era (Douglas Bennett) 293-294

Heimberg, Richard G., Liebowitz, Michael R., Hope, Debra A. \& Schneier, Franklin R. (eds). Social phobia: diagnosis, assessment and treatment (Dougal Mackay) 99

Hersen, Michael \& Van Hasselt, Vincent B. (eds). Psychological treatment of older adults: an introductory text (David Ames) 99-100

Hollin, Clive R. (ed.). Working with offenders: psychological practice in offender rehabilitation (Deborah Brooke) 100

Hollin, Clive R. \& Howells, Kevin (eds). Clinical approaches to working with young offenders (Carol Sheldrick) 96 Monograph 38) (A. M. P. Kellam) 
Holmes, C. \& Howard, R. (eds). Advances in old age psychiatry: chromosomes to community care (D. Jolley) 591-592

Hope, Debra A. (ed.). Nebraska symposium on motivation volume 43: perspectives on anxiety, panic, and fear (Isaac Marks) 490

Jablensky, A. (ed.). Epidemiological psychiatry (Terry Brugha) 95

Jamison, Kay Redfield. Touched with fire: manic depressive illness and the artistic temperament (Anthony W. Clare) 395

Johnstone, Gerry. Medical concepts and penal policy (David Tidmarsh) 95

Kaplan, Harold I. and Sadock, Benjamin J. Pocket handbook of primary care psychiatry (Scott Welch) 593

Kaslow, F. W. (ed.). Handbook of relational diagnosis and dysfunctional family patterns (Justin Schlicht) 197-198

Kiesler, Donald. Contemporary interpersonal theory and research: personality, psychopathology and psychotherapy (Phil Mollon) 295

Klonoff, Elizabeth A. \& Landrine, Hope. Preventing misdiagnosis of women. A guide to physical disorders that have psychiatric symptoms (Fiona Subotsky) 491-492

Laufer, Moses (ed.). The suicidal adolescent (Queenie Harris) 492

Lawlor, Brian A. (ed.). Behavioural complications in Alzheimer's disease (David N. Anderson) 100

Lomax, Eric. The railway man (O. Daly) 294

Lyman, Robert D. \& Campbell, Nancy R. Treating children and adolescents in residential and inpatient settings (William L. I. Parry-Jones) 197

McLynn, Frank. Carl Gustav Jung: a biography (Catherine Crowther) 396-397

Meyers, Robert J. and Smith, Jane Ellen. Clinical guide to alcohol treatment: the community reinforcement approach (Malcolm Bruce) 296-297

Mollon, Phil. Multiple selves, multiple voices: working with trauma, violation and dissociation (Harold Merskey) 297

Morgan, Steve. Helping relationships in mental illness (Peter H. Dick) 196-197

Nutt, D. J. \& Mendelson, W. B. (eds). Hypnotics and anxiolytics. Baillière's international practice and research series, vol. 1, no. 3 (James Lindesay) 94

Pallone, Nathaniel J. \& Hennessy, James. Tinder-box criminal aggression (Alec Buchanan) 589

Palmer, Stephen \& Dryden, Windy (eds). Stress management and counselling: theory, practice, research and methodology (Graeme McGrath) 594-595

Paris, Joel. Social factors in the personality disorders. A biopsychosocial approach to etiology and treatment (Mairead Dolan) 194

Phillips, Rena \& McWilliam, Emma (eds). After adoption: working with adoptive families (Stephen Isaacs) 197

Philo, G. (ed.). Media and mental distress (Raj Persaud) 194-195

Prohovnik, I., Wade, J., Knezevic, S., Tatemichi, T. and Erkinjuntti, T. (eds). Vascular dementia - current concepts (Colm Cooney) 594

Rapee, Ronald M. (ed.). Current controversies in the anxiety disorders (Peter Hayward) 296

Rommelspacher, H. \& Schuckit, M. A. (eds). Clinical psychiatry, international practice and research drugs of abuse (Emily Finch) 491

Russell, David. Scenes from Bedlam: a history of caring for the mentally disordered at Bethlem Royal Hospital and the Maudsley (Kevin Gournay) 294-295

Saradjian, J. Women who sexually abuse children - from research to clinical practice (Estela V. Welldon) 492-493

Shirar, Lynda. Dissociative children: bridging the inner and outer worlds (Dora Black) 97-98

Shorter, Edward. A history of psychiatry: from the era of the asylum to the age of Prozac (Allan Beveridge) 397
Sperry, Len. Corporate therapy and consulting (Anton Obholzer) 395-396

Sperry, Len, Brice, Peter L., Howard, Kenneth I. \& Grisson, Grant R. Treatment outcomes in psychotherapy and psychiatric interventions (Mental health practice under managed care, Volume 6) (R. H. Cawley) 195

Stadter, M. Object relations brief therapy - the therapeutic relationship in short-term work (Geoff Fisk) 593-594

Stahler, G. J. \& Stimmel, B. (eds). The effectiveness of social interventions for homeless substance abusers (Joe Herzberg) 297-298

Sturmey, Peter. Functional analysis in clinical psychology (Ailsa Russell) 98

Towl, G. T. \& Crighton, D. A. The handbook of psychology for forensic practitioners (Tim McInerny) 595-596

Tseng, Wen-Shing \& Streitzer, Jon (eds). Culture and psychopathology a guide to clinical assessment (David B. Mumford) 591

Tsiantis, John, Sandler, Anne-Marie, Anastasopoulos, Dimitris \& Martindale, Brian (eds). Countertransference in psychoanalytic psychotherapy with children and adolescents (Adrian Sutton) 298-299

Valentine, R. Asylum, hospital, haven a history of Horton Hospital (Douglas Bennett) 293-294

Varma, Ved (ed.). The inner life of children with special needs (Karen Bretherton) 94

Varma, Ved (ed.). Violence in children and adolescents (Nicky von Fraunhofer) 397-398

Violanti, John M. Police suicide: epidemic in blue (Gwen Adshead) 196

Wells, Kenneth, Sturm, Roland, Sherbourne, Cathy and Meredith, Lisa. Caring for depression (Jan Scott) 195-196

Wilmot, Stephen. The ethics of community care (Martin P. Deahl) 590-591

Wright, David and Digby, Anne (eds). From idiocy to mental deficiency (Ian Hall) 196 